\title{
IN THE ABSENCE OF MEDICAL MEN: MIDWIFE-ATTENDED HOME BIRTH, THE CHARTER OF RIGHTS AND ANTIQUE ALBERTA LEGISLATION
}

\author{
LYNNE SEARS WILLIAMS* \\ and J. CHRIS LEVY**
}

This paper takes up the question of the legal status of a midwife attending a home birth. The statutory framework for midwifery pursuant to the Medical Profession Act is analyzed, along with a historical overview of the midwifery provisions. The authors contend that the present restrictions on midwifery violate the Charter of Rights and Freedoms and they analyze the arguments available under ss. 1, 2,6,7 and 15. The philosophic and social utility of midwifery is discussed in detail. and the authors provide a comparative study of midwifery in other western industrialized nations. The authors conclude that there is neither social nor medical justification for the restrictions on the practise of midwifery contained in the Act and they call for the statutory recognition of midwifery in Alberta.
Le présent article traite du statut légal de la sagefemme qui assiste à un accouchement à domicile. Le cadre statutaire de la profession est analysé aux termes de la Loi sur les professions médicales, et un bref survol historique des dispositions relatives aux sages-femmes est présenté. Les auteurs soutiennent que les présentes imterdictions sur l'exercice des sages-femmes contreviennent à la Charte des droits et libertés; ils analysem les arguments à la lumière des al. 1.2.6.7 et 15. La valeur philosophique et sociale de la profession est examinée en détails, et les auteurs fournissent une étude comparative de la pratique dans d'autres pays industrialisés occidentaux. Ils concluent qu' il n'y a aucune raison sociale ou médicale justifiant les restrictions imposées par la Loi et ils revendiquent la reconnaissance légale de la profession de sagesfemmes en Alberta.

\section{TABLE OF CONTENTS}

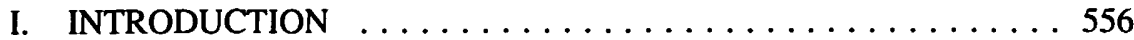

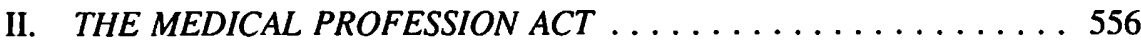

A. THE STATUS OF HOME BIRTH $\ldots \ldots \ldots \ldots \ldots \ldots \ldots 57$

B. THE TERMS OF THE STATUTE $\ldots \ldots \ldots \ldots \ldots \ldots \ldots 58$

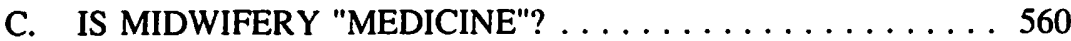

III. THE INTERESTS INVOLVED $\ldots \ldots \ldots \ldots \ldots \ldots \ldots \ldots . \ldots 65$

A. SECTION 2: FREEDOM OF CONSCIENCE ........566

B. SECTION 6: PURSUING THE GAINING

OF A LIVELIHOOD . . . . . . . . . . . . . . . . . . 567

C. SECTION 7: LIBERTY AND SECURITY

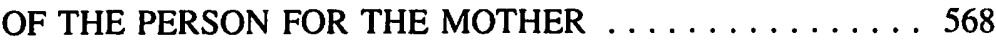

D. SECTION 7: RIGHTS FOR THE MIDWIFE $\ldots \ldots \ldots \ldots 577$

E. SECTION 15: EQUAL PROTECTION

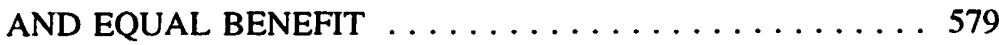

- L.S. Williams is a freelance writer with a special interest in medical ethics.

-. J.C. Levy is Professor of Law, University of Calgary. 


\section{F. SECTION 1: RATIONAL BASIS AND \\ REASONABLE LIMITATIONS $\ldots \ldots \ldots \ldots \ldots \ldots \ldots 58$}

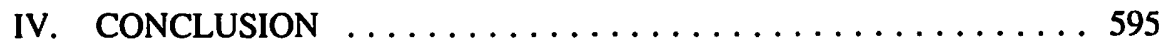

\section{INTRODUCTION}

In the fall of 1990, the Province of Alberta undertook the prosecution of a midwife who attended a rural home birth at the request of her client. This raised a number of questions. What is the status of home birth in Alberta and the legal status of a midwife attending a home birth? That is the focus of this paper. Further, how does this status affect the issue of whether midwives may attend hospital births? Many of the arguments in this analysis indirectly address this question, but it is not the central issue.

There are two persons whose rights we are concerned with in addressing these questions: the mother's and the midwife's. This is not to ignore the interests of the impending baby, but those interests are controversial, associated as they must be with the vexing question of the legal status of the unborn.' Accordingly, we shall deal with these interests indirectly. Many of our arguments will apply equally to the mother and the midwife; however, these interests are not totally coincidental. Our primary focus is going to be on the interest of the midwife.

In taking this focus, we are mindful that the fundamental validity of legislation under the Charter of Rights and Freedoms can be challenged by one charged thereunder by reference to its impact on other groups. ${ }^{2}$ We shall address Charter issues from the perspective of both the midwife and her client, the prospective mother.

\section{THE MEDICAL PROFESSION ACT}

The prosecution in question was brought under the Medical Profession Act, which makes it an offence for anyone who is not a doctor to practise medicine. Assuming for the moment that attending a birth for compensation is classified as practising medicine, the real issue in this case revolved around the very peculiar wording of s. 76:

(1) Subject to the provisions of any Act entitling a person to practise any science, therapy or system of practise, a person is guilty of an offence who

1. An article that investigates the status of the unborn in the context of criminal liability for midwives is L. Jezioranski, "Towards a New Status for the Midwifery Profession in Ontario" (1988) 33 McGill L.J. 91 at 108. In R. v. Lemay and Sullivan (1991), 63 C.C.C. (3d) 97, the Supreme Court of Canada definitively settled this issue when it supported the acquittal of two midwives on a charge of criminal negligence causing bodily harm when alleged malpractice resulted in a stillbirth.

2. R. v. Big M. Drug Mart Lid., [1985] I S.C.R. 295. Equally, the mother might herself seek standing in the lawsuit to raise these issues: Re Canadian Labour Congress and Bhindi (1985), 17 D.L.R. (4th) 193 (B.C.C.A.). 
(a) not being a registered practitioner, either directly or indirectly practises or professes to practise medicine or osteopathy, ...

(5) With respect to the practice of midwifery, subsection (1) applies only to the territory included within the limits of a city, town or village having a resident registered practitioner in midwifery therein. ${ }^{3}$

This analysis will address three issues. The first is the proper interpretation of s. 76(5) of the Act. The second is whether the midwife in fact violated the prohibition in light of the interpretation of s. 76(5). The third is whether, notwithstanding that the midwife had breached s. 76(5) as interpreted, the provisions are invalid because they violate the Charter.

\section{A. THE STATUS OF HOME BIRTH}

Home birth as practised by The Alberta Association of Midwives (AAM) is described as the planned, attended birth of a woman with a normal, healthy pregnancy. ${ }^{4}$ Such births generally have positive outcomes with comparable, and sometimes lower, infant mortality than hospital births. ${ }^{5}$ This distinguishes it from unplanned, unattended home birth with its consequent high risk and potential for disaster. ${ }^{6}$

3. Medical Profession Act, R.S.A. 1980, M-12, s.76. [hereinafter "the Act"|. Throughout this paper 'urban' means within the limits of a city, town or village; 'rural' means outside those limits and includes an incorporated hamlet.

4. The AAM is a body of midwives who provide prenatal, intranatal and postnatal services to expectant mothers and families. Some are registered nurses working only in hospitals, some are empirically trained midwives working only outside hospitals. Some, like the midwife charged by the province of Alberta, are former nurses who have allowed their status as registered nurses to lapse, and who practise midwifery in the community. Though the province of Alberta has a post-graduate nursemidwifery program, there are no nurse-midwifery practises in hospitals at the present time. A nursing degree is requisite to nurse-midwifery practice. Certified nurse-midwives (CNM's) in the United States are generally entitled to work in birthing centres or hospitals, but unless nurse-midwifery practices are granted sufficient autonomy, they tend to resemble conventional hospital care, with staff rotation and shift work, and with physician back-up. See: Alberta Association of Midwives (AAM) Standards. "Midwife Faces Charge" Calgary Herald (September 1990) Al at 2. "History of U.S. Midwifery," Report of the Task Force on the Implementation of Midwifery in Ontario (Toronto: Queen's Printer, 1987) 39 at 40 (hereinafter "Task Force"].

5. Infant mortality due to genetic anomalies and unpreventable birthing mishaps was generally assessed at 6.5 deaths per 1,000 births in 1985 . Maternal mortality in 1985 was $5.2 / 100,000$ in white populations. J.W. Williams, Obstetrics, 18th ed. by F.G. Cunningham et al., (Norwalk, Conn.: Appleton \& Lange, 1989). Recent studies indicate comparable rates of mortality whether at home or in hospital, for planned births attended by midwives. Infra, notes 6, 141, 142, 144, 145.

6. Infant mortality occurs in a proportion consistent with normal statistical probability in planned births attended by a midwife, about 3 deaths per 1,000 live births; unplanned, unattended home deliveries accounted for 120 neonatal deaths per 1,000 live births: C. Burnett et al., "Home Delivery and Neonatal Mortality in North Carolina" (1980) 244 J. Am. Med. Ass. 2741.

Infant mortality of 4/1,000 was recorded for planned, attended home births. Unplanned, unattended births were 196.6/1,000: R. Campbell et al., "Home Births in England and Wales, 1979: Perinatal Mortality According to Intended Place of Delivery" (1984) $289 \mathrm{Br}$. Med. J. 721.

\section{Études constitutionnelles}


The midwife in question, an AAM member, delivered her client's baby safely on a farm near Castor and was subsequently found not guilty of practising medicine without a licence. ${ }^{7}$ While is it not illegal per se to have a home birth, physicians in Alberta are prohibited from attending such a birth. ${ }^{8}$ The question, therefore, was whether a midwife may legally attend a home birth.

\section{B. THE TERMS OF THE STATUTE}

On its face, the Act denies any general right of the pregnant client to retain a midwife and of the midwife to act for that client. The Act has survived since 1906 with some grammatical changes. ${ }^{9}$ From 1906 to 1954 the statute outlawed the practice of midwifery within the municipal limits of a city, town or village, except by a doctor. Subsequently, the statute exempted midwives who practised rurally, or in urban areas without a medical doctor. The words "in midwifery" first appeared in $1955 .{ }^{10}$ Research has failed to disclose under what authority these words were inserted; they were not enacted by any legislative amendment and appear to be the work of the drafters of the 1955 Revised Statutes. These words create a major interpretation problem. On their face they could modify the statute to mean:

"There is no evidence to support the claim that the shift to hospital delivery is responsible for the decline in perinatal mortality...nor the claim that the safest policy is for all women to be delivered in hospital." R. Campbell \& A. Macfarlane, "Place of Delivery: A Review" (1986) 93 Br. J. Ob. Gyn. 675 at 683 .

G. Schneider \& B. Soderstrom, "Analysis of 275 Planned and 10 Unplanned Home Births" (1987) 33 Can. Fam. Phys. 1163.

R. Simmons \& S. Bernstein, "Out-of-Hospital Births in Michigan, 1972-79: Trends and Implication for the Safety of Planned Home Deliveries" (1983) 98 Public Health Reports 161.

Perinatal mortality rates are consistently low when the statistics on planned are separated from those on unexpected births. C. Anderson, "Midwifery and the Family Physician" (1986) 32 Can. Fam. Phys. 11.

Low birth weights correlated with infant mortality in unplanned home deliveries $(72.7 / 1000$ live births) contrasted with higher birth weights and low infant mortality in planned home births. (3.5/1000). M. Hinds, G.H. Bergeison \& D. T. Allen, "Neonatal Outcome in Planned v. Unplanned Out-of-Hospital Births in Kentucky" (1985) 253 J. Am. Med. Ass. 1578.

7. "Midwife Faces Charge", supra, note 4. "Judge finds midwife not guilty of illegally practising medicine" Edmonton Journal (6 June 1991) A1 at 7. (R. v. Walker (5 June 1991), C029-0555634AOI (Alta. Prov. Ct.).)

8. A 1981 Alberta College of Physicians and Surgeons (ACPS) directive said physician attendance at elective home confinements would be considered "unbecoming conduct." The College reaffirmed this stand in 1982, noting "home births represent an inherent and avoidable element of risk to mother and child." Motions 81-30 and 82-33 of the ACPS. The Alberta Medical Association (AMA) supported this stand: "The AMA remains opposed to planned out of hospital delivery in Alberta as it is felt that the safest place, for both mother and baby to deliver is in hospital." "Perinatal and Neonatal Statistics in Alberta 1989." Committee on Reproductive Care, Alberta Medical Association (AMA) 56 [hereafter "Perinatal Statistics"].

9. S.A. 1906, c.28, s.66.

10. R.S.A. 1955, c. 198, s.70(3).

Constitutional Studies 
(a) a midwife can now practise within an urban area having a resident doctor when that doctor is not qualified in midwifery, i.e. when the physician is a specialist in a discipline other than obstetrics and gynaecology; or

(b) a midwife can now practise within an urban area having a resident doctor regardless of that doctor's qualifications unless there is a legally designated "registered practitioner in midwifery" resident in that municipality.

Both interpretations appear to widen the permissible ambit of midwifery practice in a fashion not ordinarily appropriate to the consolidating function of the Revised Statutes. Though the Act explicitly describes medicine, surgery and obstetrics as functions of the registered practitioner," it defines neither "midwifery" nor the process by which one becomes a "practitioner in midwifery".

Some clues to the legislative intent are found in the Public Health Nurses Act of $1919^{12}$ in which we discover a de jure registered practitioner in midwifery who was a public health nurse. ${ }^{13}$

Accordingly, when the Revised Statutes of Alberta were compiled in 1955 there did exist a category of trained nurses who were entitled to wider exemptions from the prohibitions of the Medical Profession Act than were those who might be called unlicensed community-based midwives (i.e. women who were not registered as public health nurses but who acted as birthing assistants). Clearly, the original language of the Act from 1906 was designed to exempt the community midwives from the prohibition on practising when the practice was rural or in an urban area without a physician. The

II. The Act, supra, note 3, s. 1 (d), (c).

12. S.A. 1919, c. 187.

13. In 1919, in response to a concerted lobby by the United Farmer's of Alberta (UFA) and the United Farm Women of Alberta (UFWA) the province created the District Nursing Service, a group of trained midwives authorized to practise "in the absence of medical men." The service provided nurses to "any portion of the province where in the opinion of the Minister the services of a registered medical practitioner are not available. "They were empowered to practise midwifery and to charge fees "notwithstanding the provisions of The Medical Profession Act." Those travelling nurses attended births in remote areas of the province and were the first practitioners to provide routine medical examinations for school children. Following the introduction of the first bill to provide free hospitalization for maternity cases, Maternity Hospitalization Act, S.A. 1944, C-9, the province created the Nursing Service Act, S.A. 1950, C-45, s. 3(1), which provided "preventive and emergency" treatment in municipalities, but did not directly specify midwifery services. After 1942 the Public Health Nurses Act was no longer printed in the Revised Statutes of Alberta, but it was not repealed until 1973. Records indicate midwifery services in remote Alberta municipalities up to 1970; the Nursing Service Act was repealed in 1980. The University of Alberta training program for outpost nurses, "Advanced Practical Obstetrics", was discontinued in 1984. See: Alberta Legislative Assembly, Scrapbook Hansard (7 February 1918 to 19 April 1921) pp. 85, 99; Public Health Nurses Act, S.A. 1919, C-187, ss. 39, 46. K.S. Brighty. "Alberta Shows the Way" (1938) The Canadian Nurse 240; K.B. Colley, While Rivers Flow: Stories of Early Alberta (Saskatoon: Prairie Books. 1970); Annual Reports of Dept. of Public Health, Provincial Archives of Alberta; "Appendix 1: A History of Midwifery in Canada," Task Force, supra, note 4 at 223-24. 
inclusion of the words "in midwifery" in the Act in 1955 may have been an attempt to combine the existing exemption for "registered practitioners in midwifery" (the public health nurse) and the community midwives into one provision.

Linguistically, the result is rather unhappy, to say the least. It becomes even more unsatisfactory with the repeal of the Public Health Nurses Act in $1973^{14}$ and the subsequent demise of the outpost nursing training program. This historical approach to interpretation seems to rule out option (a) above, and favour option (b). If this is correct, it follows that there are now no longer any restrictions on the territory within which an unlicensed community midwife may practise midwifery since there are no longer any "registered practitioners in midwifery" in legal existence, nor have there been since 1973. Whatever the social utility of such a result, it is a very curious by-product of an apparently innocent amendment in the process of producing the 1955 Revised Statutes. This suggests a third option, namely that the practice of midwifery was restricted by the 1955 amendment to "registered practitioners in midwifery" (the public health nurse) and that the historical exemption for the community-based midwife was totally eliminated. This, too, would be an extraordinary result to arise from a process of consolidation and would render the protective terms of the Act nonsensical.

It seems most probable that the ultimate interpretation of $s .76(5)$ of the Act is to preserve the right of the community midwife to practise both rurally and within those urban areas lacking both a physician and/or a "registered practitioner in midwifery." The result is the distinct uneven treatment of midwives within Alberta based not only on their own geographical location, but also on the geographical location of others over whom they have no control, namely clients and physicians.

\section{IS MIDWIFERY "MEDICINE"?}

The relevant text of $\mathrm{s.} 77$ of the Act reads:

A person shall be held to practise within the meaning of section 76 who:

(c) either

(i) prescribes or administers any treatment,

(ii) performs any operation or manipulation, or

(iii) applies any apparatus or appliance,

for the prevention, alleviation, or cure of any human disease, ailment, deformity, defect or injury..."

In the prosecution of $R$. v. Walker the crown conceded that the practice of midwifery outside urban limits was not an offence, but contended that Walker professed to "diagnose

14. Supra, notes 9 and 13. Repealed by Public Health Nurses Repeal Act. S.A. 1973, c. 81, s. 1.

15. The Act, supra, note 3, sec. 77 (1) (c)(i),(ii),(iii). 
or treat any human disease, illness, deformity, defect or injury" contrary to 5.77 of the Act when she assisted at the home birth of a VBAC (vaginal birth after cesarean) mother. ${ }^{16}$ The Crown argued that a C-section scar qualified as a "deformity, defect or injury" and that Walker had overstepped the bounds of midwifery practice by attending the birth. ${ }^{17}$

In the definition of medicine the Act includes the practice of surgery and obstetrics, but the words "surgery" and "obstetrics" are not further defined. ${ }^{18}$ Strictly speaking, unless a midwife is found guilty of practising "obstetrics," she may not be guilty of practising medicine under the terms of this section, though she may still be perceived to be violating the "practitioner in midwifery" provision in s. 76(5) of the Act.

The term "midwifery" is excluded from the definition of "medicine" though a special register permits the practice of medicine, surgery and midwifery for a limited period of time for certain physicians. ${ }^{19}$ By not confining the process of birth to the notion of "obstetrics" the Act attempts to avoid the pitfall of some American statutes in which midwives were acquitted of practising medicine without a licence because childbirth was perceived as a normal physiological function and not a disease.

A Texas court, starting with the same premise ... referred to the practice of medicine as treating or offering to treat a person for a disease, deformity or injury, or effect a cure thereof. The court held that the evidence that the midwife has assisted a woman in childbirth would not support a claim under the statute since childbirth was not a disease. ${ }^{20}$

Conversely, under the terms of some other medical acts, midwives have been convicted because they were found guilty of "having treated a physical condition" specifically defined as pregnancy. ${ }^{21}$

16. R. v. Walker, supra, note 7 at 23-25.

17. Ibid. at 23-25, 366.

18. The Act, supra, note 3, s. 1(e).

19. Ibid. s. 23.

20. M. F. Forrest, "Natural Childbirth: Rights and Liabilities of the Parties" (1978-79) 17 J. Fam. L. 309 at 328-29, referring to Banti v. State (1956), 289 S.W. $2 d 244$ (Texas). See also Leigh v. Board of Registration in Nursing (1985), 481 N.E. 2d 1347 (Mass.). In that case, a registered nurse, engaged in midwifery in the community, was found not guilty of practising medicine. Leggett v. Tennessee Board of Nursing (1980), 612 S.W. 2d 476 (Tenn.) declared that midwifery did not constitute the practise of nursing or medicine and that the Tennessee State Nursing Board had no right to revoke a nurse's license because she was practising lay midwifery.

21. Bowland v. Municipal Court (1976), 556 P. 2d 1081 at 1086-87 (Cal.), determined that lay midwives violated the terms of the Business and Professions Code by treating a "physical or mental condition." Similarly, Smith v. State ex rel. Medical Licensing Board (1984), 459 N.E. 2d 401 at 403 (Ind.), declared that birthing assistance was "treating" the condition of pregnancy, and that pregnancy was a "condition" reserved to physicians under the state's medical practice act. Commonwealth v. Porn (1907), 82 N.E. 31 (Mass.) held that the definition of a midwife was "a female obstetrician." This decision noted that the midwife had prescribed 6 remedies to treat patients, for "vaginal douche," "post-partum haemorrhage," "afterpains," "prevention of purulent ophthalmia in the new-born," and 
There has been little Canadian consideration of what constitutes treatment. Some provinces, like Manitoba ${ }^{22}$ and British Columbia, ${ }^{23}$ are careful to include midwifery as part of medical treatment, distinct from obstetrics, although an early Canadian precedent in 1906 noted a distinction between medicine and "midwifery, which is really the art of preserving the health of the mother and child in childbirth ... of assisting women in childbirth." ${ }^{24}$ On the other hand, in $R$. v. Ringrose ${ }^{25}$ Cooke J. had to discuss in the context of procedures inducing abortion whether the definition of "practising medicine" found in s. 77 of the Act was exhaustive. In concluding that it was not exhaustive, he referred to the exemption for midwifery found in s. 76(5) and stated:

Such an exemption would be redundant since the services undertaken by a midwife in the uncomplicated delivery of a child do not fall into the descriptions of s. $77(1){ }^{26}$

The inevitable implication of this dictum is that midwifery is embraced within the definition of "medicine" by the very virtue of the fact that it is partially exempted from the prohibitions on practising medicine, regardless of the actual definition sections themselves. In this respect Ringrose uncannily resembles Commonwealth v. Porn ${ }^{27}$ decided eighty-two years previously.

In the Alberta Act, the statute framers attempted to avoid the obstetrics versus normal physiology argument by recognizing a distinction between "midwifery", "medicine" and "obstetrics" possibly in reaction to the 1903 failed prosecution of a northern Alberta midwife. ${ }^{28}$ The Act implies that a registered practitioner performs two functions: one

"painful haemorrhoids or piles." She carried obstetrical instruments for emergencies, but rarely used them. "Although childbirth is not a disease, but a normal function of women, yet the practice of medicine does not appertain exclusively to disease, and obstetrics as a matter of common knowledge has long been treated as a highly important branch of medicine."

22. The Medical Act, R.S.M. 1970, c. M.90, s. 2(2) (d).

23. Medical Practitioners Act, R.S.B.C. 1979, c. 254, s.72(d).

24. Re: Ontario Medical Act (1906), 8 O.W.R. 766 at 779.

This early definition incorporates the basic premises of the currently accepted international definition of midwifery: "... to conduct deliveries on her own responsibility and to care for the newborn and the mother. This care includes preventative measures, the detection of abnormal conditions in mother and child, the procurement of medical assistance and the execution of emergency measures in the absence of medical help." This definition has been adopted by the International Confederation of Midwives, the International Federation of Gynaecologists and Obstetricians and used by the World Health Organization.

3. (1989), 94 A.R. 350.

26. Ibid. at 354 .

27. Supra, note 21 .

28. The Act, supra, note 3, s. 1(d), (e); s. 23; s. 76 (1)(a), (5). In R. v. Rondeau (1903), 9 C.C.C. 523 (N.W.T.S.C.), Scott J. said at 527: "There is no evidence that the defendant administered any drugs or medicines, or performed any operation in either case. It might be inferred that she was in attendance in the capacity of a midwife...." The conviction is made under the Medical Profession Ordinance C.O.N.W.T. 1898 c. 52 s.60, which provides as follows:

60. No unregistered person shall practise medicine or surgery for hire or hope of reward 
as a midwife, the other as physician. If midwifery does not qualify as the practice of medicine, why should its application be limited solely to physicians who maintain residence in a city, town, or village? Further, if midwifery by an unregistered practitioner is not an offence conducted outside those municipal limits, what makes it an offence when practised inside those municipal limits? It becomes apparent that some parties are being provided with rights or benefits that others are not, and that the midwifery profession is being unequally regulated on a territorial basis.

In Walker, it is not clear whether Adilman P.C.J. followed the dictum of Cooke J. in $R$. v. Ringrose. The Walker case produced a directed verdict of not guilty, delivered without elaboration. It is therefore left somewhat to the imagination as to what evidence was embraced in making the Walker decision.

It is doubtful whether a C-section scar would be seen as qualifying as a "deformity, defect or injury" in light of conventional medical definitions. ${ }^{29}$ Were it so to qualify, it would open the floodgates to charges of unauthorized medical practice in the community at large since very few people enter adulthood without scarring whether caused surgically or accidentally. Further, birthing assistance does nothing to actually "treat" a C-section scar, neither curing nor ameliorating it.

The Walker prosecution also spent considerable time attempting to establish the premise that VBAC constituted an inherently risky medical undertaking, since there is a statistically slight chance of a previously scarred uterus rupturing during labour. The court heard through the prosecution's expert testimony that the risk of infant mortality due to uterine rupture in women with low-transverse scars could be estimated at less than 6 or 7 per 10,000, whereas neonatal deaths from other causes was estimated at 50/10,000. ${ }^{30}$ Some studies quantify the death rate due to spontaneous rupture even lower. ${ }^{31}$

S.51 of the Ordinance provides that every person registered under the Ordinance shall be entitled to practise medicine and surgery, including midwifery ... and it was contended that this indicated the intention that wherever the terms 'medicine' or 'surgery' are used elsewhere in the Ordinance they should include midwifery. I cannot accept the view that upon that ground alone these terms should be so interpreted. It appears to me that such interpretation could be given only by an express enactment to that effect."

C.L. Thomas, ed., Taber's Cyclopedic Medical Dictionary, 13th ed. (Philadelphia: F.A. Davis Co., 1977), D9, T64.

R. v. Walker, supra, note 16 at 559-60.

The notion that VBAC is a dangerous procedure is not supported in women with low, transverse scarring, since the risk the uterine rupture is estimated at a maximum of $.22 \%$ or $22 / 100,000$. A study that evaluated 164 international medical studies found "...not a single account in the VBAC literature of the past forty years of a mother who has died from rupture of a scarred uterus, but several mothers have died due to complications of elective repeat caesarean operations...In over 21,000 planned labours after caesarean reported in the medical literature since 1984, five babies died in association with scar rupture...only one of these reported deaths occurred in the United States...(and) three of these babies died in developing countries."

The study further noted that of 18 babies whose Apgar scores were reported following uterine rupture, only two had scores of less than 7 at five minutes, indicating a low incidence of damage to the infants. C. Sufrin-Disler, "Vaginal Birth after Caesarean" (1990) I4 I.C.E.A. Rev. 3. 
The defence statistically established that there was more chance of a low-risk woman spontaneously experiencing uterine rupture than a VBAC woman, but such low-risk women are routinely allowed to labour and deliver in rural hospitals without access to blood banks or operating theatres, virtually the same conditions as found in home settings. $^{32}$

In his directed verdict Adilman P.C.J. said the prosecution had proved Walker practised midwifery, but had not proved she practised medicine, and found her not guilty. He said Walker had attended a "normal, natural and uncomplicated" birth but did not specifically rule on what constitutes the practice of medicine, nor on the territorial boundaries issue. ${ }^{33}$

There are several inferences which can be made at this point. It may be that the verdict was based entirely on the notion that Walker had not defied the underlying exemption allowed by the law and was not guilty on this basis alone.

By extension, it might be inferred that if midwifery to a VBAC mother was not the practice of medicine outside urban limits, it could scarcely be construed as medicine within them. Conversely, the view could be taken that the practice of midwifery was not the practice of medicine in these specific circumstances, but given other circumstances might well have been considered "medicine." Here, the territorial exemption would not save a midwife from prosecution.

The critical question, then, becomes what would qualify as an "abnormal, unnatural and complicated birth" and would this be the practice of medicine? Would attendance at a twin birth in the home constitute medicine? Would a midwife rupturing the amniotic membranes to induce labour qualify as medical practice?

What the Walker decision appears to do is support the proposition that the everyday practice of midwifery is not the practice of medicine, but it does not define the parameters of what may be considered "everyday." It may create the assumption that the determination of whether midwifery is medicine or not is going to be a very fact-focused thing, depending on specific circumstances and on what procedures a midwife may have performed. Could an unanticipated complication that necessitated the introduction of intravenous lines and blood plasma sway the pendulum from "midwifery" to "medicine"?

Clearly, the field is left open for saying that in certain circumstances a midwife may be seen to be practising medicine, but not in other circumstances. Midwives and mothers in Alberta were given no clear guidelines as to whether the practice of midwifery is or is not medicine, and were left in limbo as to what the boundaries actually are. Moreover, the province remains saddled with an awkward territorial exemption. Does the exemption now have no reason for existence? Present government assurances that a way will now 
be found to integrate midwifery into the mainstream of health care ${ }^{34}$ does not negate the historical legacy of what we allege are constitutional violations, nor can there be any guarantee of when, or in what form, midwifery will be legalized. Midwifery only in hospital settings would be non-responsive to the constitutional issues. Similarly, midwifery practice in the home that places severe restrictions on what sorts of women would qualify for home birthing assistance might also be non-responsive.

We question the constitutionality of both the territorial exemption and the underlying prohibition on midwifery practice throughout the province, and by extension into all provinces which do not make allowances for midwifery care in the home.

A retrospective look at the Walker decision could bring forth the conclusion that the judgment theoretically embraces Charter arguments that can be brought to the home birth issue. Equally, the view can be taken that the decision merely avoided Charter complications. Here there are two linked but analytically separate issues; the Walker case can be perceived as a specific microcosm of the national issue of midwifery access. Constitutional arguments that would have been brought in defence of Noreen Walker are arguments that are relevant across the country. Although the statutory structures in other provinces are not necessarily the same, broader constitutional arguments of the right to practise midwifery can be advanced which would have application both in Alberta and in other provinces.

To the question of whether midwifery is medicine, then, it is probably safe to say the jury is still out.

\section{THE INTERESTS INVOLVED}

It is an essential condition of the right to invoke judicial relief that the plaintiff have a protectible interest ... no "injury" or "wrong" need have been actually committed or threatened in order to enable the plaintiff to invoke the judicial process; he need merely show that some legal interest or right of his has been placed in jeopardy or grave uncertainty, by denial, by the existence of a potentially injurious instrument, by some unforeseen event, ... or by the assertion of a conflicting claim by the defendant. ${ }^{35}$

The midwife's client has a "protectible interest" in her own health and the safety of her unborn child, both of which could be in jeopardy in a hospital setting. Low-risk hospital birth in Alberta may qualify as potentially injurious ${ }^{36}$ thereby denying the client Charter

34. Infra, note 41 .

35. Madam Justice Wilson quoting E.M. Borchard, Declaratory Judgments, 2nd ed. (Cleveland: BanksBaldwin, 1941) at 27 in Operation Dismantle Inc. v. The Queen, [1985] 1 S.C.R. 441 at 480.

36. In Alberta, The Alberta Medical Association (AMA) has strongly stated their opposition to home birth, supra, note 8 . The AMA's own internal documents though, have also been clearly critical of the overuse of technology in Alberta hospitals, particularly urging their colleagues to aim to reduce the caesarean section rate. Undesirable medical results due to hospitalization have been characterized by the physician group as a vastly inflated caesarean section rate (in the city of Red Deer as high as 27\%) with consequent higher infant mortality rate for infants delivered by $\mathrm{C}$-section $(10.1 / 1,000$ 
rights of liberty, psychological, emotional and physical security of the person, and equal benefit under the law.

As an accused person, the midwife has an obvious title to attack the constitutionality of the legislation. Essentially, she is denied the right to pursue a livelihood based on geographical location within the Province. This raises questions of equality and equal protection. In addition there is an arguable impact upon her liberty and security of the person interests. The clarification of the midwife's legal status is logically interconnected with the elaboration of her client's right to an attended home birth. We therefore turn to some discussion of the possible Charter arguments that might be advanced on behalf of both or either of these persons.

\section{A. SECTION 2: FREEDOM OF CONSCIENCE}

"Fundamental freedoms tend to travel together" ${ }^{37}$ and it is tempting to put the argument that $C$ harter guarantees of freedom of conscience are basic to birthing decisions, whether in a home or hospital context. Freedom of conscience is primarily associated with religious concepts, however. ${ }^{38}$ If the home birth decision occurred in a situation where the parents had a documented conviction that home birth was necessary to the

births) and twice the chances of babies dying on Sundays in rural hospitals due to lack of skilled staff. High C-section rates were ascribed to an unwillingness on the part of physicians to administer oxytocin and "labour-sit" for prolonged labour. "Perinatal Statistics 1984" at 12. In 1989, the provincial rate of C-section was $16.3 \%$, with 13 hospitals reporting rates of $20 \%$ or higher. "Perinatal Statistics 1989" at 50; supra, note 8. Caesarean rates varied from 16.5 to $21 \%$ in 1982 in Ontario and these were considered unnecessarily high. A labouring woman in Ontario was more likely to receive a diagnosis of arrested labour at a teaching hospital than at a community hospital, and more likely to receive a C-section at the teaching hospital. Facility policies, rather than necessity, accounted for the variations: G. Anderson \& J. Lomas, "Explaining Variations in Caesarean Section Rates: Patients, Facilities or Policies?" (1985) 132 Can. Med. Ass. J. 253. The AMA says it may reconsider its opposition to home confinements if midwifery is legalized and adequate emergency back-up systems are in place. It did not specify what measures would be considered appropriate. "Report Endorses Midwives" Edmonton Journal (12 June 1991) at Al.

Electronic monitoring leads to fetal distress being over diagnosed and unnecessary repeat caesarean sections contribute to $\mathrm{C}$-section prevalence, which carries the increased risk of matemal mortality. S. Bottoms, M. Rosen \& R. Sokol, "The Increase in the Caesarean Birth Rate" (1980) 302 New Eng. J. Med. 559.

M.P.M. Richards, "A Place of Safety? An Examination of the Risks of Hospital Delivery" in S. Kitzinger \& J.A. Davis, eds., The Place of Birth (Oxford: Oxford University Press, 1978) at 66.

Low risk mothers are more likely to have a stillbirth if they have delivered at a hospital that has access to state-of-the-art technology. M. Tew, "Do Obstetric Intranatal Interventions Make Birth Safer?" (1986) 93 Br. J. Ob. Gyn. 659.

37. I. Cotler, "Freedom of Assembly, Association, Conscience and Religion" in A. Bayefsky \& M. Eberts, eds., Equality Rights and the Canadian Charter of Rights and Freedoms (Toronto: Carswell, 1985) 123 at 133.

3*. I. Cotler, "Freedom of Conscience and Religion" in G.A. Beaudoin \& E. Ratushny, eds., The Canadian Charter of Rights and Freedoms, 2d ed. (Toronto: Carswell, 1989) 165 at 172 . See also: R. v. Big M Drug Mart Lid., [1985] I S.C.R. 295; Re A-G. B.C. and Board of Trustees of School District No. 65 (1985), 19 D.L.R. (4th) 166 (B.C.S.C.). 
expression of their religious beliefs or social structure, s. 2 rights would apply. This could be the case with certain community groups which hold that "separateness" from established social institutions should be maintained, as in Amish $^{39}$ communities, or other religious belief systems where only women may assist birthing mothers in matters obstetrical. Unless there is some radical new departure in the interpretation of "conscience," a set of beliefs specific to a particular aspect of life but not forming part of any general principles is unlikely to qualify.

\section{B. SECTION 6: PURSUING THE GAINING OF A LIVELIHOOD}

The provinces have the constitutional competence to regulate health professions, ${ }^{40}$ however no other health care profession is territorially regulated in the same fashion as midwives. Doctors, nurses, paramedics and others may move interprovincially under Charter s. 6 without undergoing radical changes in legal status. To maintain that such a midwife cannot relocate because she is not legally certified as a health professional is a catch-22 proposition: no certification exists because midwives have not been accorded a legal status, because no certification process exists. ${ }^{41}$

Section 6(2)(b) of the Charter appears to provide a discrete intraprovincial right to pursue the gaining of a livelihood. If this is so, then intraprovincial restrictions on such a right based on geographical location and on the adventitious movements of others are clearly vulnerable to attack. However, in Law Society of Upper Canada v. Skapinker ${ }^{42}$ the Supreme Court of Canada restricted this provision by reading it in conjunction with s. 6(2)(a), providing a right to interprovincial mobility. Accordingly, s. 6(2)(b) now appears only to prohibit barriers to gaining a livelihood that are a function of movement from one province to another. Thus, there may seem to be an indirect barrier of interprovincial movement in pursuit of a livelihood. The problem with this is that in $R e$ Taylor and Institute of Chartered Accountants of Saskatchewan ${ }^{43}$ it was held that different provinces may adopt different schemes for regulating professional qualifications and practise even if the effect is to deny interprovincial mobility.

39. P. Armstrong \& S. Feldman, A Midw'ife's Story (New York: Arbor House, 1986).

to. P. Blache, "Mobility Rights" in The Canadian Charter of Rights and Freedoms, 2d ed. supra, note 38, 303 at 311 .

41. To date the Report of the Task Force, supra, note 4 is the most extensive study on the ways and means of integrating midwifery into the mainstream of Canadian health care. In the summer of 1989 an application for certification to the Alberta Health Disciplines Board was made by the Alberta Association of Midwives (AAM). Following lengthy hearings and submissions from interest groups and the public, the Health Disciplines Board recommended the legalization of midwifery and the development of home birth guidelines. The provincial government said they would strike a task force to develop regulations to legalize midwifery. "Task force expected to rewrite midwifery rules" Edmonton Journal, (7 June 1991) at A7.

42. [1984] I S.C.R. 357.

43. (1989), 59 D.L.R. (4th) 656 (Sask. C.A.). 
In light of the cases of Black v. the Law Society of Alberta ${ }^{44}$ and Re Taylor and Institute of Chartered Accountants of Saskatchewan, ${ }^{45}$ it is not clear whether a prima facie violation of s. 6 exists. (Even if a prima facie violation does exist, s.6(3)(a) \& (b) may well save it.) However, assuming a prima facie violation of $s .6$ is established at this juncture, the only possible s. 6 issue hinges on the reasonableness of Alberta's regulatory scheme.

An intriguing national picture will emerge once Ontario and Alberta have legalized midwifery and the issue of pursuing a livelihood truly becomes one where a legal profession in one province is a proscribed profession in another. In this scenario, we will see a scheme where doctors, lawyers and other professionals will have the right to move and apply to their professional bodies for licensure; the licensure will depend on the individual requirements of each province, as Charter law has already supported. However, midwives will still be in the position where their mobility status will hinge on whether a province has even recognized their profession, and they will not be able to apply for licensure in some regions because their means of gaining a livelihood will be considered illegal.

The implications of such a polarization in terms of s.6 rights will then become paramount; but more importantly the picture of access to midwifery services in terms of other sections of the Charter will also come into play. It is at this juncture that the argument could be made that restricting a midwife's mobility rights correlatively restricts a pregnant woman's access to midwifery services. We will later argue that such restriction violates s. 15 rights for pregnant women on the basis of their sex.

However, until these provinces actually produce a scheme of legalized midwifery, arguments under s. 6 and other sections will remain only theoretical abstractions.

\section{SECTION 7: LIBERTY AND SECURITY OF THE PERSON FOR THE MOTHER}

The prospect of securing patient autonomy in basic health care decision-making in areas like the birthing process will be greater than is presently the case if the American concepts of autonomy and privacy are judicially recognized in s. 7 . Whether the critical component of s. 7 will be "liberty" or "security of the person", or indeed, some combination of the two, is somewhat obscure in light of judicial pronouncements to date. Nevertheless, for present purposes this obscurity is not really significant given that autonomy and privacy interests are in fact receiving some recognition. $R$. v. Morgentaler, Smoling and Scott ${ }^{46}$ may particularly be viewed as providing inferential support for a woman's right to make choices within reasonable limits concerning birthing issues, with acknowledgement that the state has a fundamental interest in fetal wellbeing. Birth is

44. [1989] I S.C.R. 591.

45. Supra, note 43.

46. (1988), 37 C.C.C. (3d) 449 (S.C.C.). 
obviously a logical outcome of reproductive choice; the same constitutional interests are present.

\section{Security of the Person}

What, then, are the autonomy ${ }^{47}$ and privacy interests that might be involved? The standard female criticism of routine hospital birthing is that the mother's bodily privacy is invaded as a matter of routine, "for the sake of the baby." 48 A distinct but related argument is that the mother has a fundamental interest in determining both the location of the birth and the identity of those who may attend.

In planning for the birth, the decision of where to deliver can be seen as a choice of location which empowers the greater (or lesser) input by the parents. In the hospital the couple may have little bargaining power. This is not to say that all the patient's rights are surrendered with his street clothes, but a considerable number are relinquished. ${ }^{49}$

Some authors suggest that the true privacy of a home birth confinement may offer better constitutional protection than hospital birth and that the American precedent of living without unwarranted public interference translates easily into the protected childbirth context. ${ }^{50}$

Mr. Justice Brandeis characterized the right to privacy as being synonymous with "the right to be left alone"st and much of the United States case law reflects the view that personal autonomy is integral to the well-being of a democratic state. ${ }^{52}$ Enforced hospital admission precipitates a woman into a situation where her rights are often negated

47. "An autonomous individual can be defined as one who is capable of making rational and unconstrained decisions and acting accordingly." T. Mappes \& J.S. Zembaty, Biomedical Ethics (New York: McGraw-Hill, 1981) at 8.

48. S. Arms, Immaculate Deception: A New Look at Women and Childbirth in America (Boston: Houghton Mifflin, 1975) 51; S. Kitzinger, "Women's Experiences of Birth at Home" in S. Kitzinger \& J.A. Davis, eds., The Place of Birth (Oxford: O.U.P. 1978) 135; E. Barrington, Midwifery is Catching (Toronto: NC Press, 1985) 101; R.W. Wertz \& D. Wertz, Lying-In: A History of Childbirth in America (New York: Schocken Books, 1977) at 132; A. Montagu, "Social Impacts of Unnecessary Intervention and Unnatural Surroundings in Childbirth" in D. Stewart \& L. Stewart, eds., 21 Century Obstetrics Now!, 2d ed. (Chapel Hill, NC: NAPSAC Inc., 1977) 509; W.R. Amey, Power and the Profession of Obstetrics (Chicago: The University of Chicago Press, 1982) 99. M.F. Forrest, supra, note 20.

so. Particularly in the context of the home viewed as a "sanctuary." B.A. McCormick, "Childbearing and Nurse Midwives: A Woman's Right to Choose," (1983) 58 N.Y.U.L. Rev. 661 at 683.

"Privacy ... does not represent dominion over things ... but rather dominion over oneself. It defines a sphere of self-control, a sphere of decision making authority about oneself, from which one can presumptively exclude others." D.R. Ortiz, "Privacy, Autonomy and Consent" (1989) 12 Harv. J. Law \& Pub. Pol. 91 at 92.

51. Olmstead v. United States (1927), 277 U.S. 438 at 478.

52. J.J. Tachera, "A Birth Right: Home Births, Midwives and the Right to Privacy" (1980) 12 Pac. L.J. 97 at 105. 
by forced exposure to technological interventions she may not want, ${ }^{53}$ and where she is forced to accept the ministrations of attendants she does not know. Routine pelvic examinations by strangers, the presence of non-essential medical and nursing students and the very good chance that a woman's own doctor may not appear for the birth violate her sense of privacy at a very personal moment. ${ }^{54}$

The intrusion is demeaning to individuality and an affront to personal dignity. A woman's legal rights to have children without unwanted onlookers turns on a desire to enhance her individuality and human dignity. When the right is violated she suffers outrage or affront. To the extent that she may undergo anxiety or mental distress, the consequences flow from the indignity which has been done to her. The gist of the wrong in the intrusion is not, therefore, the imtentional infliction of mental distress, but rather the assault on human personality ... [and it is] wrongful because [it is] demeaning of individuality. ${ }^{\text {ss }}$

The physiological stress associated with an adverse hospital birthing experience, or the psychological aftermath of needlessly-performed procedures may or may not be as debilitating as the psychological trauma described by Mr. Justice Beetz in Morgentaler. ${ }^{56}$ However, the fact that a woman is virtually compelled to deliver her child in an institution due to criminal sanctions against urban midwifery practice outside hospitals, may in fact mean that women avoid hospitalization, seek out birthing attendants who may be unqualified, or otherwise avoid necessary assistance. It is demeaning to women to assume that they would make this choice simply because they are uncomfortable with hospital routines which may mandate degrading procedures or loss of personal power. Most

53. "While it is true that in a planned home birth complications may arise which could best be dealt with in a hospital setting, it is also true that hospital based technology may be used in an irrational and even dangerous manner and lead to complications which would not have arisen had that mother had a baby at home. The temptation to interfere with the normal by transforming it into the abnormal is too great for many hospital personnel and doctors to resist. Those of us who work in hospitals delivering babies have seen this phenomenon at close range." Excerpted from the submission of the Medical Reform Group, in The Task Force supra, note 4, at 240.

34. Canadian courts have determined that the right of personal privacy extends to male prison inmates in that they are not to be searched or viewed by female guards. Weatherall v. R., [1989] 1 F.C. 18. Personal modesty has been identified as a particularly strong reason why women of immigrant cultures are reluctant to attend hospitals for birth, because they are "accustomed to midwives and do not feel comfortable with male physicians at hospitals." The Task Force, supra, note 4, at 259.

55. T.R. LeBlanc, "Invasion of Privacy: Medical Practice and the Tort of Intrusion" (1979) 18 Washburn L.J. 205 at 218. (Emphasis added).

s6. Supra, note 46 , at 503.

Many authors have documented the side effects of adverse hospital experiences to mother and child. Commonalities include the stress associated with delivering a baby in an unfamiliar institutional environment; seemingly-uncaring caregivers and use of technology which creates unwanted and sometimes traumatic results, particularly for mothers who undergo cesarean section. Stress associated with adverse birthing experiences can seriously affect mother-infant bonding and unresolved issues due to birthing experiences can impact on women's lives for years.

See generally. E. Barrington, supra, note 48. N.W. Cohen, Open Season (New York: Greenwood Publishing Group Inc. 1991). The Task Force, supra, note 4, pp. 259-69. 
women who take such a course do it because they genuinely believe that health complications and risks both to mother and child are increased by hospital birthing. ${ }^{57}$

Since the birthing mother is attempting to protect her own interests as well as those of her unborn child, violations to her security pose a threat to two sets of interests. It is here that we may cautiously begin to view the Morgentaler analysis as pertaining to a birthing mother who wishes to deliver a baby, but not necessarily in hospital.

If an Act...forces a person whose life or health is in danger to choose between, on the one hand, the commission of a crime to obtain effective and timely medical aid and, on the other hand, inadequate treatment or no treatment at all, the right to security of the person has been violated. ${ }^{5 k}$

"Security of the person is a concept so large that the possibilities of its infringement are numerous." ${ }^{39}$ Embraced within this concept is the notion that a woman's reproductive capacity should not be the object of state control, and particularly should not be relegated to the generally impersonal control of state-legislated hospitals against her will or better judgment, simply because she is a birthing mother.

The law has long recognized that the human body ought to be protected from interference by others....

[S]tate interference with bodily integrity and serious state-imposed psychological stress....constitute a breach of security of the person. ${ }^{60}$

Before the fact of hospitalization, a pregnant client cannot make the claim that she has suffered specific physical harm infringing her interests; rather, her interests have been placed in jeopardy by the uncertainty inherent in the prospect of a prescribed hospital confinement.

Interference with physical integrity raise important moral and judicial problems ... in certain cases treatment is made obligatory by legislation; in such cases it constitutes infringement on liberty. Even though imposed for the purpose of improving the security or well-being of all persons it nonetheless may constitute a risk to this very same security. Whether following consent or not, medical treatment which implies a risk for physical integrity, constitutes an act which infringes security of the person. ${ }^{61}$

The right to maintain bodily integrity ${ }^{62}$ and dignity in a home setting, with attendants

The Task Force, supra, note 4 at 263.

Supra, note 46 at 492.

P. Garrant, "Fundamental Freedoms and Natural Justice", in W. Tamopolsky \& G. Beaudoin, eds., The Canadian Charter of Rights and Freedoms: Commentary (Toronto: Carswell, 1982) 257 at 271. Supra, note 46 at $463,465$.

Garrant, supra, note 59 at 272.

"No right is held more sacred, or more carefully guarded, by the common law, than the right of every individual to the possession and control of his own person, free from all restraint or interference of others, unless by clear and unquestionable authority of law." Union Pacific Railway v. Botsford (1891), 141 U.S. 250-51. 
she knows and trusts is a rational goal for any prospective mother. This does not imply that hospitalization will be refused if a midwife believes it necessary; rather, there is an expressed preference to complete the delivery at home if hospital confinement is not indicated.

The United States Supreme Court decisions have gradually defined the role of the state in relation to women's autonomy in childbearing. Griswold v. Connecticut $t^{63}$ overruled a state law that forbade the purchase of contraceptives by married partners. Eisenstadt v. Baird ${ }^{64}$ established the right of unmarried partners to purchase contraceptives, and Carey v. Population Services International ${ }^{65}$ further provided that minor children could purchase contraceptives. So too, Roe v. Wade ${ }^{66}$ recognized that there was an autonomy interest in the decision whether to carry a fetus to term, or have an abortion. Although recent cases may suggest greater limitations on that autonomy interest, ${ }^{67}$ it clearly still exists as a recognized interest. "These cases illustrate the constitutional protection afforded to the individual's right to acquire knowledge, and parental rights to make childbearing decisions independent of undue state influence. ${ }^{118}$

This progression of precedents will logically precipitate constitutional determinations of where and how a woman may give birth.

\section{Liberty}

There is no doubt that the issue of free procreative choice as it relates to birthing matters can be discovered in Madam Justice Wilson's view of the right to liberty, where she states "...the right to liberty contained in $\mathbf{~} .7$ guarantees to every individual a degree of personal autonomy over important decisions intimately affecting their private lives." ${ }^{169}$

Certainly the decision of where to deliver, with its attendant risks, belongs preeminently to the mother and the unborn infant she seeks to protect. If the decision of a woman to terminate a pregnancy falls "within this class of protected decisions"70 it would seem the choice of where to deliver, which does not carry with it the irreducible surety of non-being for the infant child, can readily be subsumed within the body of this first principle.

\footnotetext{
"Every human being, and thus, every medical patient, of adult years and sound mind has the right to determine what shall be done with his own body." Canterbury v. Spence (1972), 464 F. 2d 772 (D.C.Cir.).

(1965), 381 U.S. 479.

(1972), 405 U.S. 438 at $454-55$.

(1976), 431 U.S. 678.

(1973), 410 U.S. 113.

Webster v. Reproductive Health Services (1989), 109 S. Ct. 3040 and cases therein cited. Tachera, supra, note 52 at 105.

Morgentaler, supra, note 46 at 554.

Ibid.
} 
The notion that the state's legitimate interest in the protection of a viable fetus' rights mandates institutional birth settings so as to ensure the safety and wellbeing of infants initially raises two fundamental issues. The first is that by allowing legislatures to decree that only certified hospitals may provide birthing assistance it duplicates, in fine, the same problematic conditions that existed in previous criminal law on abortion. It takes "...the decision away from the woman and give(s) it to a committee... the committee bases its decision on 'criteria entirely unrelated to [the pregnant woman's] priorities and aspirations.'" 71

While it is true that selection of a birthing venue is, on its face, not as drastic an issue as to whether potential life will or will not be terminated, this does not make the threat to a woman's liberty interest any less. Nor does it reduce the possibility of overzealous protections being placed on birthing mothers in hospitals which might greatly exceed the legitimate scope of the state's intention. ${ }^{72}$

The state's "protection of fetal interests" in the hospital birth scenario further rests on the presumptive notion that governmental interests in infant well-being are somehow of more intrinsic value than the mother's penultimate interest. Such a concept is wholly repugnant when considered in the context of individual liberty entrusted to the benevolent management of government in a free and democratic society.

[A]n aspect of the respect for human dignity on which the Charter is founded is the right to make fundamental personal decisions without interference from the state... Liberty in a free and democratic society does not require the state to approve the personal decisions made by its citizens; it does, however, require the state to respect them.... The state will respect choices made by individuals and, to the greatest extent possible, will avoid subordinating these choices to any one conception of the good life. ${ }^{73}$

The state's bona fide interest in fetal well-being, as exemplified by Morgentaler, can be achieved though other mediums which assist pregnant women in making effective birth decisions, rather than making the decisions for them, as we shall later discuss.

"To be able to decide what to do and how to do it, to carry out one's own decisions and accept their consequences, seems to me to be essential to one's self-respect as a human being...." ${ }^{74}$

Canadian judicial experience on zones of privacy holds that control of one's reproduction is a highly protected constitutional value. Implicit in Eve v. Mrs. E. ${ }^{75}$ is

71. Ibid. at 555 .

72. An appropriate analogy can be discovered in Mr. Justice Beetz remarks concerning the composition and administration of abortion committees. Ibid. at 493-500.

Ibid. at 550-51.

lbid. at 549 .

[1986] 2 S.C.R. 388. A mentally retarded woman could not be forced to have a hysterectomy in order to ease the burden of care incurred by the institution in which she was confined. 
the proposition that a law restraining free procreative choice may be vulnerable to a s. 7 attack, even when the individual so affected is a person of limited mental competency. So too, Morgentaler ${ }^{76}$ offers support for an American based "zone of personal privacy" approach keyed to bodily integrity and absence of serious state-imposed psychological stress, both of which can be seen to be at risk in routine hospital confinements.

Inferential support may also flow from Tremblay v. Daigle ${ }^{77}$ where the court held that it was not willing to grant an injunction compelling a woman to carry a fetus to term. To mandate that all women must deliver their babies in hospital:

[Is to] assert that the woman's capacity to reproduce is not to be subject to her own control. It is to be subject to the control of the state.... State enforced medical or surgical treatment comes readily to mind as an obvious invasion of physical integrity. ${ }^{78}$

Whether psychological or physical trauma actually occurs in hospital is a situational issue; it may or it may not occur. For those who seek to avoid such risks, the subtlyenforced state scheme of insisting on hospital birth by eliminating alternatives constitutes a threat to a woman's liberty to make her own choices.

These decisions largely deal with the securing of autonomy before conception, or before a fetus approaches viability. Once a woman decides to carry a baby to term, does the constitutional zone of privacy become a nullity? It is hoped that Canadian jurists will not follow the lead of American state courts, where court-ordered caesareans and forced obstetrical interventions constitute a dangerous violation of a woman's right to liberty. ${ }^{79}$ One American author has proposed that a pregnant woman waives "her right to resist bodily intrusions made for the sake of the fetus when she (chooses) to continue the pregnancy." ${ }^{180}$ This suggests that the alleged conflict between maternal and fetal rights catapults a pregnant woman into the realm of public property. In fact, in the pregnancy

76. [1988] 1 S.C.R. 30.

[1989] 2 S.C.R. 530.

Supra, note 46 at 556 .

I. Grant, "Forced Obstetrical Intervention: A Charter Analysis" (1989) 39 U.T.L.J. 217. L.J. Nelson, B.P. Buggy \& C.J. Weil, "Forced Medical Treatment of Pregnant Women: Compelling Each to Live as Seems Good to the Rest" (1986) 37 Hastings L.J. 703. S. Goldberg, "Medical Choices During Pregnancy: Whose Decision is it Anyway?" (1989) 41 Rutgers L. Rev. 591. G.J. Annas, "The Impact of Medical Technology on the Pregnant Woman's Right to Privacy" (1987) 13 Am. J. Law \& Med. 213. Notc, "Rethinking Motherhood: Feminist Theory and State Regulation of Pregnancy" (1990) 103 Harv. L. Rev. 1325.

John A. Robertson, "Procreative Liberty and the Control of Conception, Pregnancy and Childbirth" (1983) $69 \mathrm{Va}$. L. Rev. 405 at 445, discussing the concept of in utero fetal therapies that did not present an undue risk to a mother's life or health. 
of a competent individual no such conflict exists. ${ }^{81}$ "Childbirth ... has the mutual goal between mother and fetus of achieving a healthy birth". ${ }^{82}$

The failure of some American cases like Fitzgerald v. Porter Memorial Hospital ${ }^{83}$ or Hulit v. St. Vincent's Hospital to have the concept of "privacy" affirmed in birthing litigation can be largely explained as the unwillingness of the courts to favour parental perceptions of proper policy over entrenched institutional perspectives. Although Bowland v. Municipal Court noted that the right to privacy has "never been so broadly construed as to include the manner and circumstances in which a woman may give birth to a baby," ${ }^{85}$ this can be perceived as an unfortunate, not to say shortsighted, American decision. None of these cases went to the Supreme Court and therefore they cannot be viewed as the final authority. The right to privacy has not yet been specifically defined as including the act of childbirth, but it has only been within the last four decades that privacy in childbirth has been institutionally denied, and mainly in North America. ${ }^{86}$ In this respect particularly, the unwritten precedent will support the centuries - old norm of birthing privacy.

Birthing safety and midwifery practice has been much investigated in a Canadian and international context. ${ }^{87}$ To the extent that safety arguments are relevant to the scope of this case, we shall deal with them in our discussion of $\mathrm{s}$. 1. To assume autonomous, informed responsibility in the childbirth decision, in the same way that parents exercise suitable discretionary powers after a child is born, is a logical prerogative of parenthood.

Pregnancy and childbirth are two points on a continuum of family autonomy. Parents have already decided to marry and reproduce, with the knowledge that the family responsibilities they assumed would not cease until their children were fully nurtured and educaled. If persons are deemed competent enough to marry, to conceive, and to educate children, and yet incompetent to choose a birth attendant, then it appears that the government distrusts its constituents. ${ }^{\mathrm{kx}}$

в1. S. Rodgers, "Fetal Rights and Maternal Rights: Is There a Conflict?" (1986) | C.J.W.L. 456.

82. $\quad$ K.M. Whitby, "Choice in Childbirth: Parent, Lay Midwives, and Statutory Regulation" (1986) 30 St. Louis Jour. 985 at 1008, commenting on H.M. Caldwell, "Bowland v. Municipal Court Revisited: A Defense Perspective on Unlicensed Midwife Practice in California" (1983) 15 Pac. L.J. 19.

83. (1975), 523 F.2d 716 (7th Circ.).

84. (1974), 520 P. 2d 99, 102 (Mont.).

85. Bowland v. Municipal Court, supra, note 21 at 1089.

86. R. W. Wertz \& D. Wertz, supra, note 48 at 77.

"A History of Midwifery in Canada" in Task Force, supra, note 4 at 197-227.

J. Towler and J. Bramall, Midwives in History and Society (London: Croom Helm, 1986) at 245.

The Task Force, supra, note 4 is the most extensive Canadian document produced on the subject of midwifery. Ontario has introduced a legislative bill that will legalize midwifery and establish a College of Midwives, "Ontario to allow midwifery as a profession" Calgary Herald (3 April 1991) at A3. The Province of Alberta announced their intention to develop midwifery legislation following the Walker trial and a recommendation from the Alberta Health Disciplines Board, but gave no definite datc when such legislation could be expected. "Report Endorses Midwives" Edmomton Journal (12 June 1991). 
For present purposes, the exercise of liberty may be partially defined as the right to take informed risks that pose no discernible harm to oneself or society. American case law and Charter litigation show that such freedom does not allow one the right to place a minor child in certain jeopardy. ${ }^{89}$ Nor should liberty imply the right to violate statutes or expedite death for a third party, where death can ordinarily be avoided. The issue of home birth is dissimilar, however, in that low-risk confinements do not suppose a definitely predictable risk to infant or maternal health. Indeed, they may protect newborns and mothers from iatrogenic disease. ${ }^{90}$ An unborn child has the right to non-negligent treatment, ${ }^{91}$ but competent midwifery can provide, at the least, this standard of care. The issue of parental autonomy holds that birthing decisions should not arbitrarily be relegated to physicians and the province. ${ }^{92}$

The issue then becomes whether a violation of these privacy interests constitutes an infringement of the $\mathrm{s.7}$ guarantee of fundamental justice. We hold that "the deprivation of a pregnant woman's right to security of the person can never comport with fundamental justice. ${ }^{93}$ The principle of fundamental justice embraces some historical right to individual autonomy. Reference re Section 94(2) of the Motor Vehicle Act ${ }^{94}$ makes it clear that fundamental justice is neither confined to matters of procedure nor has it an undefined situational quality.

Our argument therefore approaches that which has been used in some of the classic American cases interpreting the due process provisions of the United States Constitution. In particular, these cases embrace the notions of individual autonomy as a component of due process. We do not argue for the economic aspects of autonomy that the American cases seem to enshrine, but rather, the proposition that choice by the mother in the birthing process incorporates security and liberty interests so fundamental that any legislative attempt to restrict this expression of individual autonomy is prima facie a violation of s. 7 .

F.G. Jacobs, "Non-Canadian Constitutional Experience Relevant to the Fundamental Freedoms Provision of the Charter" (1983) 13 Man. L.J. 599 at 603; the courts have also upheld the right of the Province of B.C. to surgically implant a shunt to drain excess cerebral spinal fluid from a severely retarded boy following brain damage from meningitis, in opposition to the parents wishes. Re: S.D., [1983] 3. W.W.R. 618 (B.C.S.C.)

90. Dr. Caldeyro-Barcia, former head of the Intemational Confederation of Gynaecology and Obstetrics, goes so far as to state that "iatrogenia [doctor-caused illness] is the main cause of fetal distress" in E. Barrington, supra, note 48 at 122.

9. $\quad$ E.H.W. Kluge, "The Right to Life of Potential Persons" (1976-77) 3 Dalhousie L. J. 837 at 846.

92. "Simply because the decision of a parent ... involves risk does not automatically transfer the power to make that decision to some agency or officer of the state." Parham v. J.R. (1979), 442 U.S. 584, at 603 (1979).

93. Supra, note 46 at 478 .

94. [1985] 2 S.C.R. 486. 
It is true that there is no Canadian decision supporting this view, equally however, there is no Canadian decision that we are aware of clearly opposing this view. Therefore we submit that at least the matter remain open to our courts.

\section{SECTION 7: RIGHTS FOR THE MIDWIFE}

Two totally distinct arguments surface in this section. First, s. 7 encompasses some notion of economic freedom or right to the opportunity to make a living. Second, s. 76(5) of the Act imposes no-fault criminal liability on a midwife that violates guarantees of liberty and security.

\section{Economic Freedom}

While many cases do restrict the scope of $\mathbf{s . 7}$ to non-commercial or non-economic matters, ${ }^{95}$ a possible interpretation of these cases in light of their precise facts is that they refuse to acknowledge an outright right to make a living as opposed to a right to the opportunity to make a living. ${ }^{96}$ So, too, there is obvious hostility to allowing corporate freedom to be protected under $5.7,{ }^{97}$ and this sometimes takes the form of broad language denying any protection to economic interests. ${ }^{98}$

There may be a possible argument that restrictions on intraprovincial mobility so severe as to deny opportunity to practise a profession or calling violate the "liberty" interest embraced in s.7. The analogy here is with such cases as Re Mia and Medical Services Commission of B.C. ${ }^{99}$ The problem with the analogy is that this case involved restrictions on the territorial ambit of the practice of a doctor otherwise fully qualified to engage in a lawful activity. In the case of the midwife, the issue is the more fundamental one of whether the activity is indeed one that is lawful. Accordingly, the argument involves an analogical extension into as yet uncharted territory and its acceptance is unpredictable.

\section{No-fault Liability}

We have argued that it is legal for a midwife to deliver a baby outside the boundaries of any city, town or village in Alberta, or within those boundaries if there is no resident registered physician. It becomes illegal as soon as a medical doctor takes up residence. Thus a midwife in urban practice is subjected to shifting standards of law, variously losing

95.

See Reference Re ss. 193 and 195(I)(c) of the Criminal Code (1990), 109 N.R. 81, where Lamer J. would totally exclude individual economic interests, but the rest of the court does not go that far. Accordingly, the matter still remains open.

9. Re: Abbotsford Taxi Ltd. and Motor Carrier Commission (1986), 23 D.L.R. (4th) 365 (B.C.S.C.).

97. Irwin Toy Ltd. v. R., [1989] 1 S.C.R. 927.

98. Pinehouse Plaza Pharmacy Ltd. v. R., [1988] 3 W.W.R. 705 (Sask. Q.B.).

99. In Mia, an administrative decision to deny a medicare billing number to a qualified physician unless she practised in a specified location violates "libeny" interest protected by s.7. (1985), 17 D.L.R. (4th) 385 (B.C.S.C.); also Wilson v. B.C., [1988] 2 W.W.R. 1 (B.C.C.A.), leave to appeal refused, [1988] 2 S.C.R. viii. 
and regaining legal status. It is not possible for her to be secure in her position in such circumstances. Generally, a person is entitled to a reasonable opportunity to know what her legal status is and to conduct herself accordingly. Although midwives in rural areas have been granted the right to practise, this benefit and the continuance of their livelihood depends not on any intrinsic standard of competence but rather on the continued nonincorporation of that area as an urban community. Further, it then becomes necessary to rely on the territorial absence of a third party, the registered physician.

The essential question here is the rationality of determining legal status by the movements of an independent human being over whom the accused has no control. Sometimes the presence of persons is required to establish that something occurred in a legally-prescribed manner, as in witnessing wills, but there are few situations where legality flows from the absence of another person. ${ }^{100}$ In this case, the commission of a criminal offence is established solely on the basis of a third party occupying the same territory; a medical doctor's mobility determines the midwife's liability. It is this feature of the midwife's case that provides the main argument on this aspect of $\mathbf{s .} 7$.

The Act infringes a fundamental principle of legality, namely that law and legal rights cannot change capriciously. A stolen apple does not become a found apple because its possessor has scaled the boundary fence between the farmer's field and the road. Similarly, a midwife's legal rights cannot fluctuate because a medical doctor decides to relocate. $^{101}$ One of the fundamental premises of the law is that punishment is only appropriate when the accused is personally responsible for the situation in question. While it is true that the midwife knowingly attends the birth, her legal status depends on surrounding circumstances not under her control. In short, fault is not present. The penalty for attending a home birth illegally is a fine of up to $\$ 1,000$ or up to three months imprisonment. ${ }^{102}$ The midwife's right to liberty, specifically to remain at liberty and not to be imprisoned for attending a birth, is in jeopardy. The result is that the midwife is at the mercy of others over whom she has no control and indeed of whose movements she may well be totally unaware. We would argue that this creates an offence violative

100. Certain sexual acts can lose the benefit of an exemption from liability if a third party is present. (Criminal Code R.S.C. 1970, c. C-34, s. 159). However, there is no suggestion in the cases of liability being imposed if the third party is present without the knowledge or at least the implied consent of the participants.

In 1923 the annual report of the Department of Public Health noted:

"In the past year three new districts were opened and two closed.... The district of Bear Lake automatically closed, the services of a doctor being available to the community, and Miss Redmond, nurse in charge resigning from the staff. The district of Beaver Lodge also closed, the services of a doctor being available." The underlying rationale here may be economic, the government being unwilling to fund midwives in the presence of a doctor, who collected his own fees and imposed no financial burden on the government. Department of Public Health Annual Report 1923, at 33. Provincial Archives of Alberta, accession No. 68.145 .

The Act, supra, note 3, s.80(1)(a); (b)(i),(ii), (iii); (2). 
of the minimum standards of liability set out in Reference re Section 94(2) of the Motor Vehicle Act. ${ }^{103}$

\section{E. SECTION 15: EQUAL PROTECTION AND EQUAL BENEFIT}

What makes the act of a midwife providing birthing assistance legal if performed one foot outside an urban boundary, but illegal if enacted one foot inside that same boundary? On the face of it, such a statute clearly produces a situation in which practising midwives and pregnant women receive differential treatment. Since midwives remain midwives and pregnant women remain pregnant women wherever they are located, the statutory distinction that attends home birth has no rationale whatsoever on the basis of their own intrinsic qualities.

The terms of the Act create differential treatment in several ways:

(a) Midwives who may have essentially the same standards of competence do not have the same legal right to practise, or to pursue employment opportunities. Those located in a rural area have an unfettered right to practise, whereas midwives in an urban area have only a qualified right.

(b) Midwives in an urban area may only practise if there is no doctor resident in that area. Their status automatically changes if a doctor becomes resident. Practically speaking, this means very few midwives may legally practise in urban areas. Midwives in rural areas only undergo a change in status if there is an annexation of their area by a city, town or village with a resident physician. Practically speaking, this means very few midwives may not practise in rural areas.

(c) The same midwife whose practice involves attending clients in both urban and rural areas finds her legal status transformed from area to area and from time to time, as she travels in and out of municipal boundaries. In effect, the Act makes her unequal with herself.

(d) Pregnant women who wish to avail themselves of the services of a midwife are legally entitled to do so only if they choose to give birth in a rural area. They become party to an offence if they desire the attendance of a midwife at a home birth in an urban area. They incur both unequal access to a health care option and unequal liability if they exercise that option, compared with their rural sisters.

It becomes obvious that some midwives in urban areas are treated differently by virtue of the adventitious presence of another person with a specific personal characteristic;

103. Supra, note 94 at 486. If the proper interpretation of the Act is that it imposes strict rather than absolute liability, these arguments may well not apply. We do not address the difficult issue of whether strict liability may itself violate $\mathrm{s.7}$ in certain circumstances. 
namely, the professional qualification of an M.D. They thus appear to become less equal than the doctor and further become unequal with respect to each other.

It might have been appropriate in the past to argue that s. 15 guarantees of nondiscrimination on the basis of sex had been infringed by this circumstance. Since the statute discriminates against midwives in favour of doctors, and given that most midwives are women and most doctors are men, it unfairly benefits persons of the male sex to the detriment of persons of the female sex. From an historical perspective such an argument has considerable potential validity. Even today a case can be made that systemic gender discrimination may exist within the medical profession. However, changing enrolment patterns in medical schools mean that the field of medicine is neither presently nor likely to be in the future the exclusive domain of men that it once was. Though it may be correct for the moment to say that the field is dominated by men, including all older male physicians near retirement, a challenge on enumerated grounds of sex discrimination may be difficult, both because of these changing demographics and because of the unavailability of precise statistics on the location and practice patterns of female family physicians.

Unfortunately, despite the problematic nature of the rural/urban inequities, as a consequence of the present case law, there is no basis for a s. 15 claim based on geographic inequalities. Of particular concern is the fact that forcing women to rely on the services of physicians in hospitals for births, and negating alternatives by outlawing midwifery in urban areas, may be perceived as discrimination against them on the basis of their sex. Such a result is clearly prohibited under the terms of Brooks $v$. Canada Safeway Ltd. ${ }^{104}$ It is possible to argue that pregnant women in some parts of Alberta may well be treated unequally compared to rurally-located pregnant women in Alberta, in that they receive unequal access to the health care option of midwifery in the home.

It is also submitted that pregnant women are being treated differently than other women with reproductive capacity; specifically, they are treated differently than women who choose to have abortions. Provincial law allows a woman to exercise the choice of having an abortion up to a specified number of weeks of gestation, but does not statutorily limit the option to rural women, or urban women. All women, despite their location of residence, have the option of choosing not to reproduce.

Pregnant women are, however, given limited options under the terms of the Act as to who they may engage as a birthing assistant, and differing options depending on their place of residence. This may also qualify as unequal treatment under $\mathbf{s}$. 15, though it is not an argument we are prepared to elaborate at this time.

These issues are presented as a matter for consideration only and because they have some relevance to the issue of rational basis under s. 1. Any discussion of $\mathrm{s}$. 15 
necessarily involves the question of the appropriate remedy. If the exemption for midwives in the Act does violate equality rights for pregnant women a court could strike down either the injunction or the underlying prohibition. We would argue that it is the underlying prohibition that should be struck down.

\section{F. SECTION 1: RATIONAL BASIS AND REASONABLE LIMITATIONS}

The proper test for the application of $\mathrm{s} .1$ is found in $R$. v. Oakes. ${ }^{105}$ This test is extra-judicially summarized by Mr. Justice David McDonald:

There are "three important components of a proportionality test":

First, the measures adopted must be carefully designed to achieve the objective in question. They must not be arbitrary, unfair, or based in irrational considerations. In short, they must be rationally connected to the objective.

Second, the means, even if rationally connected to the objective in the first sense, should impair "as little as possible" the right or freedom in question...

Third, there must be a proportionality between the effects of the measures which are responsible for limiting the Charter right or freedom, and the objective which has been identified as of "sufficient importance." 106

The obvious objective of the Act is to promote a legitimate state interest in ensuring fetal well-being. Whether the means chosen are truly necessary is the issue, particularly whether they are justified considering the violation of Charter rights which ensue.

The initial argument must be made that the routine institutionalization of birthing women is not carefully designed at all. Rather, automatic hospitalization of women, though perhaps expedient for the caregivers attending them, is a sledgehammer approach to the achievement of positive birth outcomes. Hospitalization should ideally be the final parameter of a pendulum approach to birthing. In such a scheme:

1) Low-risk women are offered the choice of a home or hospital location with a competent midwife or physician;

2) Women are presented with the option of transfer to a birthing centre or hospital if labour is prolonged or has complications;

3) The active-care hospital is primarily reserved as the venue for high-risk obstetrics, particularly for neonates or mothers perceived as being at risk.

Ins. [1986] I S.C.R. 103.

106. D.C. McDonald, Legal Rights in the Canadian Charter of Rights and Freedoms (Toronto: Carswell, 1989) at 77-78. 
Enforced hospitalization for every pregnant woman is an arbitrary standard by which birth is being conducted when others could as easily be implemented. While it may be argued that the measure is not completely irrational, thus conforming to the first standard of a proportionality test, neither is it completely rational. Hospitals and doctors are not rationally necessary to ensure safe births. To prove this, a considerable body of medical and political evidence must be considered. The argument that follows is designed to show that the legislative object of s. 76(5) of the Act is not demonstrably justified in a free and democratic society.

\section{The Philosophy and Utility of Home Birth}

In 1906 a governmental decision set into law the concept that birth should be attended by doctors. However, when it was realized that doctors were not always available, an exemption allowed midwives to attend births "in the absence of medical men." 107 It is moot to question whether that policy was appropriate for the time, but almost one hundred years later we can question whether that decision is appropriate today.

Two clearly different sets of issues are involved in a discussion of rational basis: one of philosophy and one of utility. The predominant question is that there is an obvious infringement on self-determination as it relates to the physiological event of childbirth. Does the evidence now show that reproductive autonomy should continue to be interfered with in Alberta in light of the existence of autonomous midwifery elsewhere in Canada ${ }^{108}$ and in other western industrialized nations? ${ }^{109}$ The most compelling evidence to answer these questions in the negative is that other western democracies do not see fit to interfere with reproductive autonomy in the way we do. Despite a considerable body of evidence, particularly from continental Europe, to support the proposition that midwifery is totally acceptable as a health discipline, the extraordinary issue of physician dominance in North America has served to prevent the emergence of a new category of health care provider.

Supra, note 13.

wox. Ontario intends to legalize midwifery. The federal government also funds nurse-midwifery in its northernmost territories, including Northern Alberta, though policy stipulates that ideally women will be transported to territory hospitals for the birth of their babies. Telephone communication with nurse Helen Rebeyka at Health and Welfare Canada nursing outpost, Fox Creek. Alberta, to Lynne Sears Williams. Also "A History of Midwifery in Canada" the Task Force, supra, note 4 at 197. Inuit women have begun to protest the mandatory evacuations out of their region to centrally-located hospitals, and are demanding local midwifery care. Calgary Herald (1 December 1990) at B12. Supra, note 87.

The Netherlands, Denmark, Britain, Wales, Australia, Finland, Sweden, Norway, France and parts of the United States (among others) all have varying schemes of midwifery care, most incorporating midwifery care into hospital settings or birthing centres. An overview of midwifery practice internationally is found in S. Kitzinger, ed., The Midwife Challenge (London: Pandora Press, 1988). A brief anecdotal discussion is "Observations of Midwifery in Other Countries." Task Force, supra, note 4 at 39-63. 
The second issue of utility focuses on the social construction of midwifery. Is it economically feasible in a socialized scheme of medical care and is it morally justifiable, i.e. is it safe? It is impossible to achieve absolute equality in law and it is fair to say that not all the benefits of a state can be distributed equally. Regional disparities are inevitable, but in this instance a benefit that is less costly to the province is being withheld and a more expensive one, hospitalization, is required. By effectively denying the home birth option to city dwellers, the Act forces pregnant women to enter the hospital for the birth process. Thus the province retains its monopoly on the delivery of health care ${ }^{110}$ and perpetuates its role as employer and employee in the annual fiscal dance of government-funded hospital grants and expenses billed back to the government due to hospitalization. The province cannot provide physician coverage for every area of the province, ${ }^{11}$ nor could it provide equal access to midwifery care, but the provision of equal opportunity for midwifery services is attainable. Given that there are low-cost options available, why should every person be forced to utilize high-cost options?

In a privately-funded scheme of medical care, the argument can be made that insisting on routine hospital delivery burdens women economically and creates a substantial gap in care available to disadvantaged mothers and infants. ${ }^{12}$ While by no means as substantial, direct economic costs in a socialized system of care must be borne by mothers and partners for private rooms, transport to hospital, and child care for youngsters left at home. Urban dwellers probably carry less of this burden than rural dwellers. These costs are minute compared to the increasing burden taxpayers are expected to assume, as the rising rates of intervention and iatrogenia transform the prospect of routine labours and short hospital stays into complicated births requiring extra staff, more medication and longer periods of hospitalization, most notably in increasingly common caesarean births. This argument does not begin to address the issue of greater psychological cost, when a birth that could have been routinely and safely concluded is transformed into a medical textbook scenario, nor does it take into account the subsequent cost to the infant and mother, who may find their interaction seriously disrupted by the medical event. ${ }^{113}$ The

110. "Even if doctors receive the same payment for attendance at a home birth as they do for a hospital birth... the hospitals could lose a reliable and predictable source of revenue when women choose to bear their children in their own homes." Alberta NDP Background Paper, Domiciliary Midwives and Homebirths: A Safe, Practical Alternative (18 August, 1983) [unpublished].

111. The Alberta Conservative government's initiative in the 1970 s and 1980 s to allegedly provide universal access to health care by constructing more rural hospitals resulted in many empty facilitics, because physicians were unwilling to relocate in rural areas. "Small Hospitals Pay Off in Votes" Calgary Herald (30 June 1987) at A1-A2. "Rural Hospitals Face Critical Shortage of Surgeons" Calgary Herald (9 July 1988) at A1-A2. "Alberta's New Doctors Prefer Urban Lifestyle" Calgary Herald (12 November 1987).

112. McCormick, supra, note 50 at 686: and see infra, note 158.

113. Success in breastfeeding was impaired if mothers did not have access to their babies in the first four hours after birth: only $50 \%$ of babies born in a hospital were nursed within this time frame. "Even these 20 babies were nursed for less than 15 minutes before being taken away from the mothers for six to twelve hours." Rubber nipples and formula were offered as substitutes. At six months age. only $6 \%$ were breast-feeding exclusively. "Physicians and nurses must realize that breast-feeding can be severely disrupted by the early introduction of bottles, that breast-feeding is extremely important 
"spare no expense" approach that occurs in socialized medical schemes often involves very high hidden costs that parents would likely reject if they were sufficiently informed.

It is possible to ascribe a mercenary motive to the statute-framers and speculate that physicians' groups aided in its drafting, so as to protect their market share of patients in high population centres. Many writers do perceive this sort of monopoly ${ }^{114}$ and such claims can be supported by historical research ${ }^{115}$ but financial gain probably was not the only motive behind this statute. ${ }^{116}$

to many mothers, and that changes in nursery routines and allowances made for the breast-feeding mother can be important for successful breast-feeding." J. Newman \& B. Wilmot, "Breast-Rejection: A Little-Appreciated Cause of Lactation Failure" (1990) 36 Can. Fam. Physician 449 at 450, 452. An extensive collection of physician dominance and anti-trust commentary in the U.S.A. is documented: B.A. McCormick, supra, note 50 at 669-74.

"Sir: In looking over the proposed amendments to the Ontario Medical Act, I find a provision to the effect that it shall be within the power of each Territorial Division to license midwives. This I wish to oppose most strenuously as being totally uncalled for in a country which is flooded with doctors who have been thoroughly trained, and are therefore much more competent to deal with these cases than a midwife. I contend that as we have spent some of the most valuable years of our lives in the study of what is said to be a "noble profession", as well as considerable money, that we should be protected most stringently against the meddlesome interference on the part of old women, and further to this is to many of us country doctors a very renumerating part of our business, and we would not like to be made by Legislative measures to pay from $\$ 2$ to $\$ 5$ a year for the support of an Act which takes money out of our pockets, by placing it within the power of others who have never spent a farthing, nor lost an hour for the sake of becoming properly educated, to attend cases of confinement.

Where I am located I have to contend with two of these old bodies and a quack, who I must say have been prelty successful in their attendance, as they get about 60 cases a year, which would amount in my hands to a very decent living for my small family."

Letter to the editor, Canada Lancet Vol. 6, 1873-74. From the text of "A History of Midwifery in Canada" in Task Force, supra, note 4 at 207.

115. An overview of the historical conflict between midwives and physicians and the development of midwifery as a profession can be discovered in J. Towler \& J. Brammall, Midwives in History and Society (London: Croom Helm, 1986). J.B. Donegan, Women and Men Midwives: Medicine, Morality and Misogyny in Early America (London: Greenwood Press 1978). J.B. Litoff, The American Midwife Debate (New York: Greenwood Press, 1986). J. Donnison, Midwives and Medical Men: A History of Inter-Professional Rivalries and Women's Rights (London: Heinemann, 1977). Wertz \& Wertz, supra, note 48.

It is noteworthy to take into account the historical context of medical care available when the Act was first passed. In 1906, the legislative justification of s. 76(5), and indeed of many of the legislated medical codes across Canada, rested on the notion that only doctors could provide the necessary safeguards to promote the state's interest in safe birth outcomes. This perception has persisted up to the present time. Without exception, however, these codes were mandated at a time when hospitalization for maternity cases was extremely rare and there were virtually no advantages hospitals could offer birthing women that could not as easily be met at home. Most births, whether doctor or midwife-attended, occurred in domiciliary settings. 
This sort of legislative deus ex machina might appear justifiable if the intent were to guarantee rural physicians unlimited clientele, so as to attract medical coverage in outlying communities. In point of fact, both rural and urban physicians have limited time for maternity care, and could be better served by the implementation of midwifery services. ${ }^{177}$ Present-day doctors are unlike their historical counterparts in that they are not engaged in private enterprise but their fees, set by the government, are perceived as woefully inadequate to their level of training. ${ }^{118}$ More and more physicians are opting out of obstetrical care regardless of their urban or rural place of residence, both for reasons of lifestyle and fear of malpractice suits. ${ }^{119}$

In many cases physicians are perceived as elitist professionals who distance themselves from their obligation of patient care. ${ }^{120}$ The abuse of hospital emergency wards in city hospitals for non-emergency complaints has partly been attributed to the inaccessibility of doctors after 6:00 p.m. ${ }^{121}$ It is noteworthy that the Public Health Nurses Act ${ }^{122}$ was initially implemented to provide maternity services to pregnant rural women, and the territorial exemption of the $A c t^{123}$ presumably continued this role, yet the on-going force of history saw rural maternity services decrease as years went by. Whereas once rural women could count on the attendance of a midwife, if not a doctor, for their confinements, as transportation became more readily available they were expected to

Nor was the standard of professional training afforded by physicians necessarily superior to the standards of midwives; indeed some research indicates that physician attended births had significantly worse outcomes than midwife-attended births. Most notable was the medical school of thought that prescribed douches of caustic ingredients for the prevention of childbed fever, and extreme reliance on obstetrical interventions like forceps, causing a higher percentage of damaged infants than those delivered without doctor-assistance. The standard obstetrical education for doctors required viewing only four births prior to licensing. In 1929 the Canadian Medical Association Journal noted a disturbing trend:

"The death rate per 1000 maternity cases delivered by midwives was 2.8 , by doctors 6.9 and in institutions 14.9. The last figure, which includes only cases untouched before admission, is surprisingly high..."

We may infer, then, that the rational basis of the Act may be seen as initially flawed. See generally, "A History of Midwifery in Canada" in Task Force, supra, note 4 at 197-232, 211, 219. At the present time no province seems to have geographical restrictions on the practice of midwifery similar to those found in Alberta, although historically such restrictions were not unknown, especially in the Maritimes. Current legislation either expressly outlaws the practice of midwifery entirely, or more usually, involves a complex set of definitions that are capable of being interpreted either way. "Midwives may stem the tide of F(amily) P(ractitioners) out of Obstetrics" Medical Post (31 May, 1988) at 6.

"M.D.'s abandoning obstetrics" Calgary Herald (23 September 1990) at Al.

119. Infra, note 166 at 50.

120. M. McCaffery, "Why Women Want Midwives" (1984) 30 Can. Fam. Physician 1975.

121. "In a radio interview on Christmas Day, 1987, the head of the Emergency Department at the Ottawa General Hospital indicated that a third of the patients seen that day were sick with minor illnesses because their doctors' offices were closed ..." from "An Agenda for Action" in Report of the Advisory Committee on the Utilization of Medical Services (Edmonton: Queen's Printer. 1989) at 81.

122. S.A. 1919, c.187.

123. Supra, note 3, s. 76. 
travel increasing distances to avail themselves of birthing assistance. Indeed, the level of maternity service in Alberta had so declined that by the time of the Walker case, the birthing mother, Kathleen Charpentier, was told she could not arrange to have her baby at her local hospital because the hospital did not allow VBAC trials-of-labour. ${ }^{124}$ She was told to arrange her delivery at a regional hospital more than 90 miles from her residence. ${ }^{125}$

In terms of actual safety, it would be more rational to allow midwifery practice within rural limits where easy access to hospital could be obtained if necessary, and where the majority of births are conducted. Physician attendance, more costly to the taxpayer, could then be reserved for difficult cases, whether urban or rural.

It also makes sense to ask if the time has come to introduce a health care provider who will be readily available to pregnant clients, and who may reinstate a level of personal care that was present at the time of the 1906 statute, when birthing assistants, whether doctors or midwives, attended most births at home. ${ }^{126}$

The rural/urban distinction may have been intended as a practical matter of social utility. Since it is difficult to prevent the unlawful practise of midwifery in less-densely populated areas, and since any statute must be enforceable, the effectiveness of rural restriction is limited. Although there may be an element of validity in this distinction, the scarcity of police service did not prevent the Crown in Alberta from charging a midwife with unlawful practice, though she delivered a baby on a farm outside the limits of a rural town. ${ }^{127}$

The statute must assume that the state has a valid interest in protecting infant and maternal health, and has concluded that midwifery constitutes an unacceptable standard of care compared to that provided by practitioners registered under the Act. In Bowland the court declared the state had a legitimate interest in ascertaining the credentials of those professing to practise a health discipline, and prohibited the practising of unlicensed midwifery. ${ }^{128}$ Under the Act, however, the practice of midwifery is not an offence in rural Alberta so the Bowland principle would seem to have no application.

Rural hospitals in Alberta do not permit VBAC trials-of-tabour unless they are equipped with a blood bank, operating theatre and the services of a surgeon and anethetist; this is considered medically advantageous in light of statistics that indicate the chance of uterine rupture. $R$. v. Walker, supra, note 16 at 560. L. Sears Williams, "Relations Between Midwives, MD's Appear to be Thawing Despite High-profile Trial" (1991) 145 C.M.A.J. 497 at 498.

125. R. v. Walker, supra, note 16 at 560 . L. Sears Williams, ibid. at 497.

126. By 1929, only 24.5 per cent of births in Canada took place in hospital, but this does not tell us how many were medically unattended, since many doctors still came to births in homes. "A History of Midwifery in Canada" in Task Force, supra, note 4 at 218. 
The intent of the statute might then be stated as permitting the unregulated delivery of health care (midwifery) in areas where physicians are not available, so as to allow some standard of birthing assistance for expectant mothers. This intent might be reasonably phrased as "Where we can provide physicians, who provide a better standard of care, we will not permit midwives, who provide a lesser standard, to practise. Where we cannot provide physicians we will not prosecute midwifery." The implication that midwifery care is better than no care at all would provide an element of situational legal immunity for midwives, while essentially maintaining that midwifery is unlawful. Thus, it may be argued, the midwife is in a more difficult legal position than is the prostitute. Prostitution in and of itself is not an offence, although clearly predictable aspects of associated behaviour are illegal. ${ }^{129}$

The desire to protect citizens from uncertified or unacceptable health care presupposes that the standard of care provided by physicians will exceed that of midwives, a confidence that may be misplaced given new evidence on maternal and infant health. It further raises the question why midwives' standards would be considered acceptable in the absence of a physician, but are nullified by a doctor's presence. A further problem with the Act is that it assumes doctors' standards are better than midwives' but does absolutely nothing to regulate the standards of midwifery which it in fact allows. The fact that such standards were partly articulated by the Public Health Nurses Act ${ }^{130}$ from 1919-1973 was largely the effect of happenstance. The Medical Profession Act ${ }^{131}$ never undertook to recognize midwifery, not even by the courtesy of defining it for the medical profession. The Act's provisions could briefly be stated as: "Whatever midwifery is, it is not allowed, though sometimes we will exempt it from prosecution."

The Act also produces the rather bizarre effect of protecting precisely the activity one would hope it would proscribe: midwives who deliver inferior maternity care. Provided such a midwife operates outside municipal limits, she retains the right to practise and enjoys a legal immunity she does not deserve. Truly hazardous standards may eventually result in charges of criminal negligence, but only after someone has suffered injury or death.

The debate over whether physicians or midwives produce better birth outcomes has been laid to rest in much of the industrialized western world in which midwifery often enhances the delivery of health care, particularly in hospital settings and birthing centres. ${ }^{132}$ Whether a consensus on home birth safety will ever be reached is questionable. Physician and nursing groups in North America have been reluctant to

\footnotetext{
129. A prostitute is only prevented from residing in a bawdy house or soliciting. She is entircly free to be a prostitute. Criminal Code, R.S.C. 1970, c. C-34, ss. 210, 213.

Supra, note 122.

Supra, note 3, s.76.

Kitzinger, supra, note 109.
} 
accept midwifery standards embraced by the World Health Organization, and they have largely influenced public opinion to this date. ${ }^{133}$

Briefly, what are the standard premises of midwifery, and why do proponents consider midwife attendance at a home birth a safe alternative to the present system of hospital births? The midwife is considered a qualified specialist on healthy, normal pregnancies, which account for the majority of all deliveries. She may recommend home or hospital confinement to her clients and will refer problems in pregnancy that are out of the scope of her expertise to appropriate health care providers. ${ }^{134}$ She does not employ anaesthetics or instruments in the labouring stage, and relocates a home birth to a hospital setting if complications arise or the birth process is prolonged. ${ }^{135}$

Midwifery protocol sometimes excludes home deliveries for premature, multiple or breech deliveries, and insists that all clients have arrangements for appropriate medical back-up during the course of the pregnancy and delivery. ${ }^{136}$

\begin{abstract}
In Holland, every woman, midwife, and doctor knows that only a spontancous and uncomplicated delivery can take place at home. Therefore, everybody is convinced of the importance of frequent and extensive prenatal examinations.... As a precondition for home confinement we now ask for the absence of any indications of abnormality. ${ }^{137}$
\end{abstract}

Statistics show that planned home births attended by a midwife have less morbidity than hospital births with comparable, sometimes better, mortality.

...all morbidity measures favoured babies born at home. Hospital-born babies far exceeded home-bom babies in respiratory distress, poor Apgar scores, birth injuries, neurological abnormalities, infections and

133. While perhaps extreme, one editorial in an American medical journal declared that "Home birth is an anti-intellectual, anti-science revolt ... by the nihilists who want no prenatal care. Home delivery is maternal trauma and child abuse", as quoted in E. Barrington, Midwifery is Catching, supra, note 48 at 131. The Society of Obstetricians and Gynaecologists of Canada, the College of Physicians and Surgeons and the College of Nurses (CON) of Ontario opposed home births in their submissions to the Ontario Midwifery Task Force, "though the CON indicated a willingness to reconsider their position when midwifery is legally established." Task Force, supra, note 4 at 239, 244 and 420.

13. As an autonomous professional, the referral to another appropriate health care professional might be to an obstetrician, for an abnormal condition of pregnancy, for example, or to a physiotherapist for remedy of a muscular problem.

135. These standards are expressed in the International Definition of Midwifery, supra, note 24. Limitations on midwifery scope of practice include the assessment and monitoring of women during pregnancy, labour and the post-partum period and of their newborn babies, the provision of care during normal pregnancy, labour and post-partum period and the conducting of spontaneous normal vaginal deliveries, Task Force. supra, note 4 at 86.

13. . "The Framework of Practice." in Task Force, supra, note 4, makes extensive recommendations of characteristics necessary for midwifery practice, at 93-115 and recommends that protocols be set that contraindicate birth in a home setting.

13. G. Gloosterman, "The Dutch System of Home Births" in The Place of Birth, supra, note 48, 85 at 86. 
the need for resuscitation and oxygen. Forceps were used 21 times more frequently in hospital births. Mothers' data show that hospital births [had] ...heavy medication and resort to caesarean deliveries. Despite hospital reliance on episiotomy, ${ }^{13 \%}$ lacerations were still substantially higher ...[and] post-partum haemorrhage was three times as likely following a hospital birth. ${ }^{130}$

Other studies echo these findings, including mention of higher birth weights in home birth babies, ${ }^{1+0}$ low mortality in planned, attended home births, ${ }^{1+1}$ and that midwives effectively screen high-risk patients from home birth patients, with consequent negligible infant mortality. ${ }^{142}$ Standards of prenatal, intrapartum and postpartum care, peer review and informed consent agreements constitute some of the elements of the modern practice of midwifery. ${ }^{143}$

Formalized medical training focuses on the pathology of disease, rather than the physiology of normal birth, often creating the problem of iatrogenic illness due to the over-reliance on drugs and technical interventions seen as efficacious. ${ }^{14}$

An episiotomy is a surgical incision of the vaginal wall performed shortly before birth to temporarily widen the passage, often performed routinely in hospital settings to shorten the last moments of labour and prevent vaginal tears. An intact perineum is considered the hallmark of a competent midwife delivery. E. Barrington, supra, note 48 at 49 . "Dr. J.W. Williams' first obstetrics textbook in 1903 had been scathing about what he considered the "fad" of routine episiotomy; in the 1920s he advocated routine episiotomy as a part of normal conservative obstetrics." "A History of Midwifery in Canada" in Task Force, supra, note 4 at 218.

Y. Brackbill, J. Rice \& D. Young. eds., Birth Trap: The Legal Low'dow'n on High-Tech Obstetrics (St. Louis: C.V. Mosby Co., 1984) at 60, discussing L. Mehl et al. "Outcomes of Elective Home Births; a Series of 1146 Cases" (1977) 19 J. Reprod. Med. 281. J. Williams, Obstetrics, supra, note 5, at 697. A comparison of intervention rates between home and hospital delivery showed the percentage of interventions and the caesarean rate climbed sharply in Denmark following its move to reorganize obstetrics from home to hospitals, even though Denmark has a socialized system of midwifery care in hospitals. The Dutch system, with its organization of midwife-attended home and hospital births, did not exhibit an increase in interventions. S. Scherjon. "A Comparison Between the Organization of Obstetrics in Denmark and The Netherlands" (1986) 93 Br. J. Ob. \& Gyn. 68489.

E.R. Declercq, "Out of Hospital Births, U.S. 1978: Birth Weight and Apgar Scores as Measures of Outcome" Public Health Reports at 63.

141. M. Hinds et al., supra, note 6.

142. C.A. Burnett et al, supra, note 6.

143. AAM Standards of Practice, supra, note 4.

14. M. Tew, "The Case Against Hospital Deliveries: The Statistical Evidence" in The Place of Birth. supra, note 48. A hospital cycle of intervention in a low-risk birth might occur as follows: A woman is admitted to hospital in strong labour. She is assessed as progressing normally, but becomes stressed as contractions proceed. A dose of Demerol is prescribed to ease the pain. Shortly thereafter, contractions cease and the woman and her support partner begin efforts to restimulate labour. Labour restarts after the Demerol entirely wears off, but this is several hours later. Because of the lapse of time, hospital staff decided to monitor the baby and restrict the mother to bed with an internal monitor. This further slows down the labour. As the process recommences, the mother becomes very tired and staff administer an epidural anaesthetic so she will not suffer too much. Following this, the mother cannot tell when to push with contractions, and finally concluding she is too fatigued to continue, the physician uses forceps to remove the baby, after cutting a large episiotomy. The baby is born exhibiting respiratory depression, which persists for many hours. It will be removed 
The temptations of over-enthusiasm are greater in obstetrics because of the mixture of complicated and uncomplicated cases that are treated side by side. ${ }^{145}$

Medical studies indicating the dangers of hospital confinement are legion. They range from unnecessarily high caesarean rates, ${ }^{146}$ to dangers of oxytocin-induced labour, ${ }^{147}$ to the hazards of fetal heart monitors ${ }^{148}$ and recently the ineffectiveness of fetal heart monitors in preventing neurologic damage. ${ }^{149}$ An oft-cited advantage of hospital birth is the capacity for continuous electronic fetal monitoring (EFM), but studies now show that EFM is frequently ineffective at preventing birth injuries, is costly, and its use is largely undertaken by physicians who wish to prevent claims of malpractice from parents of birth-injured children. ${ }^{150}$

Side-effects of medication on infants, ${ }^{151}$ repressed maternal-infant bonding ${ }^{152}$ fatherinfant bonding, ${ }^{153}$ even delayed speech patterns in toddlers ${ }^{154}$ are documented side

to a special care nursery for assessment, while the mother receives vaginal stitches and is returned to her room. A baby in such a condition will often receive an anti-narcotic to reduce the effects of the anaesthesia. The mother and baby will sleep off the effects of the medication for many hours, which may adversely affect their bonding process. "A depressed infant, if not acidotic and asphyxiated, will respond to resuscitative measures. The baby is asleep for the same reason the mother is asleep; they have been administered a drug which selectively depresses the central nervous system ... it is important to know why a baby is depressed. Is the baby asphyxiated or has it been anaesthetized?" in W.A. Bowes Jr., "Obstetrical Medication and Infant Outcome: A Review of the Literature" (1970) 35 Monographs of the Society for Research in Child Development 1 at 15; M.P.M. Richards, in The Place of Birth, supra, note 48 at 75.

145. M.P.M. Richards, "A Place of Safety? An Examination of the Risks of Hospital Delivery" in The Place of Birth, supra, note 48 at 81.

S. Bottoms, et al, supra, note 36 at 559-63. Anderson et al., supra, note 36. "Perinatal Statistics", supra, note 36.

W.A. Liston and A.J. Campbell. "Dangers of Oxytocin-Induced Labour to Foetuses" [1974] Brit. J. Med. 606-07.

Fetal scalp electrodes can cause extensive lacerations to an infant if incorrectly applied. M. Atlas and D. M. Serr, "Hazards of Fetal Scalp Electrodes" [1976] The Lancet 648.

A controlled trial of infants monitored electronically compared to infants monitored by auscultation (stethoscope) showed no improvements in neurologic development or reduction in perinatal mortality. K.K. Shy et al, "Effects of Electronic Fetal-Heart-Rate Monitoring, as Compared with Periodic Auscultation, on the Neurologic Development of Premature Infants" (1990) 322 N.EJ.M. 588.

"Routine electronic monitoring in normal and high-risk pregnancies is now the standard; providers who do not use it flirt with the danger of a major suit should an infant be brain damaged, despite the growing body of evidence that such unfortunate outcomes are seldom linked to birth events." R.J. Bulgur \& V.P. Rostow, "Medical Professional Liability and the Delivery of Obstetrical Care" (1990) 6 J. Contemp. Health Law \& Policy 81 at 85.

151. Infant respiratory distress, poor sucking reflex and poor performance on standardized behaviour tests lasting up to 30 days after birth are documented side effects of medicated labour. Bowes, supra, note 144 at 15.

152. A. Witten, "Assessing the Effects of Perinatal Events on the Success of the Mother-Infant Relationship." Studies of Mother-Infant Interaction, H.R. Schaffer, ed.. (London: Academic Press, 1977) at 403.

133. J. Richman and W.O. Goldthorp, "Fatherhood: the Social Construction of Pregnancy and Birth" in The Place of Birth, supra, note 48 at 157. 
effects of hospital birth. There is some evidence that post-partum depression is a function of hospitalization and that the deleterious effects of obstetric events can be documented for years. ${ }^{155}$

Doctors and hospital administrators generally cite decreased infant mortality rates (IMR's) as grounds for declaring that hospital births are safer than home births, since IMR's have dropped significantly since hospital birthing became the norm. ${ }^{156}$ However, a major life insurance company in an actuarial study did not attribute the decrease solely to routine hospitalization, but rather to the decrease in the numbers of infants being born to each mother and to a better standard of living. ${ }^{157}$ Premature labours to teenage mothers account for almost two-thirds of infant mortality ${ }^{158}$ and greater medical expertise does not necessarily result in better outcomes for these mothers. ${ }^{159}$ Many health critics believe that midwives can provide better health protection than can registered physicians ${ }^{160}$ particularly for the socially disadvantaged. This is largely the result of the midwife's mandate to provide education about nutrition and cessation of harmful activities

N.M. Ringler et al., "Mother to Child Speech at Two Years - Effects of Early Post-natal Contact" (1975) 86 Jnl. of Pediatrics 141.

E. Barrington, Midwifery is Catching, supra, note 48 at 121-23.

There are a wide range of statistics available on this topic, with numbers sometimes varying widely. The data set on calculating infant mortality has changed through the years to complex formulas which take into account infants born at term who survive birth but die within a week; infants who are born prematurely, survive more than a week, but die within 28 days of birth; and infants who are born at term. but die within the first year. Thus statistical evaluations are fraught with difficulty: "Infant Mortality Rate" as used herein refers to infants bom live, but who die within the first year of life. The IMR of 33.8/1,000 live births in the U.S. in 1946 fell to its 1986 level of 10.6/1,000, but was still almost twice as high as European countries that provide socialized midwifery. Whether the critical component in reducing mortality is midwifery care or access to socialized medicine is difficult to say. At least one study suggests that prenatal midwife care is better than prenatal obstetrician care for reducing IMR's, infra. at note 159. Statistical Bulletin: "Infant Mortality, 1986: National and International Differences" (1988) 69:2 Metropolitan Life Foundation 2.

Increased availability of contraception, abortion, better nutrition and better management of neonates at risk have contributed to the drop in IMR's. Statistical Bulletin: "Infant Mortality in the United States," (1978) 59:3 Metropolitan Life Foundation 2.

The largest percentage of infant mortality occurs in premature and low-birth weight births to teenage mothers. "[O]verall risk of infant fatality was associated with maternal social class, and access to and availability of effective prenatal and infant health care." Statistical Bulletin. supra, note 156 at 8.

The IMR of 10.3/1000 live births in Madera County. California tripled when a nurse-midwifery program was discontinued and obstetricians took over the service. Prematurity increased by 50 percent. B.S. Levy: F.S. Wilkinson and W. Marine, "Reducing Neonatal Mortality Rate with NurseMidwives" (1971) 109 Am. J. Obstetrics and Gynaecology 50 at 51.

"Perinatal Epidemiologist Dr. Marsden Wagner, of the World Health Organization, testifying at an inquest told the court that Canada's rate of "medically managed childbirth was both dangerous and extremely costly...(that) a strong midwifery system with its emphasis on the "normal" acts a crucial balance to the obstetrical system, which focuses on pathology... Canada, with its otherwise highly respected health care system, universal access to medical care and high standard of living, is not among the top countries in birth outcomes and is far behind in the development of midwifery." Midwives Coalition brief to the Health Professions Legislative Review, (Third submission, October 1985) appendix 13, at 12 (hereinafter "Midwives Coalition"]. 
during pregnancy, as well as extensive prenatal care and information. Such a claim is not intrinsically provable however, and the debate as to whether infant mortality for term pregnancies increases or decreases with hospitalization is at best inconclusive. ${ }^{161}$

Some parents in North America believe birth is a process that should be confined to hospitals, and that the presence of medical staff ensures a safe standard of care. ${ }^{162} \mathrm{~A}$ growing number of other parents and health professionals across Canada are demanding midwifery care after becoming unconvinced of the necessity and losing confidence in the safety of hospital birth as it is presently conducted. ${ }^{163}$ Physicians themselves are beginning to request legalized midwifery in an effort to reduce their patient load ${ }^{164}$ and some hospitals have welcomed the idea of midwifery practice becoming available to them. ${ }^{165}$

An obstetrical crisis is expected to occur as more and more physicians abandon obstetrical practice for reasons of lifestyle and ever-increasing malpractice premiums. ${ }^{166}$

E. Alberman, "The Place of Birth" (1986) 93 Br. J. Ob. \& Gyn. 657-58. An independent report commissioned by the Alberta Health Disciplines Board evaluated 65 intemational and national studies as to the safety of home and hospital births. It concluded there was no evidence to show that the safest place for a woman to give birth was either home or hospital. "There is some evidence that, with proper risk assessment, selection and care, low risk women may safely give birth at home." D. Kypa, "Summary of the Midwifery Literature Review" Peat Marwick Stevenson and Kellogg (4 January 1991).

162. Staff competence at hospitals may be less vigorous than the public deserves. One author estimated that U.S. medical students could graduate with only three to nine weeks of obstetrical instruction, and without any clinical experience. On nursing training, an Alberta report noted "... a large variation in the amount of clinical experience provided ... new graduates were able to work in newborn and postpartum nursing but had deficient skills when nursing mothers in labour." It estimated clinical training to vary from 16 to 160 hours. As to hospital standards, following at two-year investigation, the government of Alberta fired the board of trustees at a rural hospital for failing to ensure patient safety at a 90-bed facility. Sources: J.J. Tachera, supra, note 52 at 113. P.A. Field, excerpts from "Report of the Advanced Obstetrics Advisory Committee to the Department of Manpower" (Edmonton: Queen's Printer, 1979) "Two Hills Hospital Board Dismissed" Calgary Herald (14 December 1990) at B6.

163. In a public opinion poll conducted by Environics Research Groups in August, 1986, 43 percent of the respondents said they felt delivery of babies by midwives should take place in either home, hospital or birth clinic; only 26 percent believed deliveries should be confined to hospitals" in Task Force, supra, note 4 at 108. "Ontario Plans Legalization of Midwifery" Calgary Herald (24 January 1986) at A3. M. McCaffery. "Why Women Want Midwives" supra, note 120. "Demand for Midwives Skyrockets in Canada" Calgary Herald (3 October 1985) at D7.

C. Anderson, "Midwifery and the Family Physician" (1986) 32 Can. Fam. Physician 11-15. "Midwives May Stem the Tide of FP's (Family Practitioners) Out of Obstetrics," supra, note 117. An Ontario hospital surveyed on its views of midwifery noted: "...the implementation of midwifery, with its expanded holistic approach, would lead to an overall improvement in the health of both women and children and to improved obstetrical technique and overall quality of care within hospital settings," Task Force, supra, note 4 at 235. 
A hospital proposal for nurse-midwife units operating independently in hospitals has been made to help avert the oncoming crisis, but has been met with mixed reviews. ${ }^{167}$ In any event, the fact that such a solution would involve both trained nurses and a hospital setting makes it unresponsive to the constitutional issues. Economists are questioning whether the doctor-midwife battle has more to do with physicians' territorial imperatives than safety. ${ }^{168}$

It is vital to realize that much of the medical professions' reluctance to consider the efficacy of home birth has been coloured by a veneer of historical prejudice that in more recent times has been pseudo-scientifically supported. The standard medical criticism of home birth is that it produces high infant mortality, but this can largely be explained as a failure of medical studies in this century to separate planned home birth statistics from unplanned, unattended emergency home births ${ }^{169}$ and a failure of medical schools to promote emphasis on the normal case. ${ }^{170}$ Nor do many physicians understand that competent midwifery can safely screen high-risk pregnancies from low-risk, reserving those at higher risk for in-hospital delivery only. ${ }^{171}$ The goal of midwives and physicians is ultimately the same: healthy babies and healthy mothers. There is no reason to suppose that this outcome can only be achieved through hospitalization, or only with doctors.

To deny the right of women to give birth in circumstances of their choosing, or to effectively limit that choice by denying access to midwives ${ }^{172}$ is to assume that a consenting adult is not able to determine her own best health care options. This sort of paternalism imposes psychological, physical and social burdens ${ }^{173}$ on individuals that

Malpractice premiums for obstetricians escalated in 1987 to $\$ 8,250$ from $\$ 4,900$ in 1986 . The fee in 1984 was $\$ 1,950$. A family practitioner practising obstetrics paid $\$ 1,675$ in 1987 , compared to $\$ 800$ for a family practitioner not practising obstetrics. Task Force, supra, note 4 at 103.

"Obstetricians and family physicians increasingly report that they are eliminating the obstetrical portion of their practices or reducing the provision of care to patients who are at identifiably high risk because they fear being sued and do not want to accept the high cost of liability insurance." Bulgur, et al., supra, note 150,81 at 83 .

167. "Hospital Approves Nurse-Midwives Plan: Foothills Project May Deliver as Many as 250 Babies a Year" Calgary Herald (25 September 1990) at BI. "Calgary Grace Hospital, Doctors Opposed to Midwife Plan" Calgary Herald (26 September 1990) at B3. Economists say fight between doctors and midwives has more to do with competition and market share than good medicine. "Midwifery Legal Fight Blasted" Calgary Herald (17 September 1990) at A9. "Midwives, 'Less Expensive Than Doctors'" Calgary Herald (14 September 1990) at B6. Supra, notes 5 \& 6 .

M.P.M. Richards, "A Place of Safety? An Examination of the Risks of Hospital Delivery" The Place of Birth, supra, note 48 at 81. "Midwives Coalition" supra, note 160.

Supra, note 142.

Limits can be placed on an individual's autonomy either by interfering with the individual's freedom to exercise choice or by interfering with the choicemaking process. J.S. Zembaty, "A Limited Defense of Paternalism in Medicine" Biomedical Ethics, supra, note 47 at 57.

McCormick, supra, note 50 at 686. 
exceed the ambit of any responsibility of the state to protect maternal and fetal health. ${ }^{174}$ We assume a "woman will act in her own best interests, but she presumptively will act in her child's interests also." 175 The "opportunity to evaluate knowledgeably the options available and the risks dependent upon each" ${ }^{176}$ belongs to the client. The civil law of liability and malpractice can provide effective protection for health interests as efficiently as the present hospital system, without the paternalism and risk associated with institutional confinements. Many factors of normal living involve substantially more risk to human life than the prospect of a planned home delivery. In 1978, a 24 year-old woman in the United States was five times more likely to die as a result of an accident, ${ }^{177}$ than to die in childbirth. At age 35 , she was at ten times the risk of dying from cancer than from childbirth. ${ }^{178}$

The over-regulation of the entire childbearing population in an effort to eliminate isolated instances of morbidity or mortality is not a philosophical position that can be justified in this, or any other legislative action. One may further question whether it is truly the state's responsibility to restrict pregnant women from incurring risk either to themselves or to their potential progeny. If this is so, then regulation of diabetic or hypertensive women who wish to become pregnant becomes an issue. Similarly, obese women will have to be prevented from becoming pregnant, and those who are at risk because they are over 35 years of age. Once a state becomes the watchdog of reproductive risk, women's rights and freedoms concomitantly become at risk.

In 1906 the Act may genuinely have sought to protect the child-bearing population by promoting safe birth outcomes. Indeed it may perhaps still seek to do so. The impression

174. "...legal paternalism justifies state coercion to protect individuals from self-inflicted harm, or in its extreme version, to guide them, whether they like it or not, toward their own good." J. Feinberg, Social Philosophy (Englewood Cliffs, N.J.: Prentice-Hall 1973) at 45.

"... the state's compelling interest on protecting matemal and child health must be effectuated by the least drastic means ... by training and practice altematives which do not impermissibly interfere with the protected childbirth decision. Tachera, sipra, note 52 at 119.

McCormick, supra, note 50 at 686.

176. Camterbury v. Spence, supra, note 62 at 780.

"One of the direct consequences of the principle of personal autonomy is the right to what may be referred to as self-determination. Once a person is capable of making free and informed decisions, he should have the right, without interference and within the limits imposed by his living in society, to make decisions affecting himself. This rule of self-determination is particularly important where decisions affect physical or mental integrity. It is designed to respect the power of the individual to make decisions, to ensure a personal "sphere of intimacy" and to guarantec the individual a measure of control over his own life." Law Reform Commission of Canada, "Some Aspects of Medical Treatment and the Criminal Law" (Working Paper No. 28) (Ottawa: 1986) at 12.

177. Statistical Bulletin: "Leading Causes of Death Among Women" (1982) 63 Metropolitan Life Foundation 12.

178. Statistical Bulletin: "Geographic Variations in Mortality from Cancer," (1982) 63:3 Metropolitan Life Foundation 3. The risk of maternal death following childbirth is estimated at $5.2 / 100,000$ in white populations. However, this figure includes blended low and high risk patients, and reflects the greater likelihood of post-partum hacmorrhage following hospital use of anaesthesia. J. Williams, Obstetrics, supra, note 5 at 697. 
left, however, is now one of oppression rather than protection, for the restrictions involved are much broader than is necessary for the attainment of the protective objectives. ${ }^{179}$ Routine hospital birthing is not necessary to attain these objectives. Further, in the international context, World Health Organization statistics demonstrate that those industrialised countries with the most extensive midwifery services also have the best birthing outcomes regardless of the place of birth. ${ }^{180}$ It is instructive that the United States, which relies almost universally on hospital birthing, still has a significantly high infant mortality rate. ${ }^{181}$

Though it is indeed a leap of faith to move from the legalization of midwifery to the socialization of midwifery services, ultimately less tax dollars would be required to provide extensive prenatal counselling, home birthing and post-partum care than is required for routine hospitalization. ${ }^{182}$ The social utility of lower government costs for better returns in and of itself suggests the need for substantial changes in Alberta's present restrictive policies, and it may be argued by extension, of all other provincial medical codes that do not make provision for midwifery services.

\section{CONCLUSION}

There is neither social nor medical justification for the restrictions on the practice of midwifery contained in s. 76(5) of the Act. Accordingly, those restrictions lack any sufficient present rational basis. In terms of proportionality there is a tremendous body of evidence that suggests there is a fundamental irrationality underlying both the legislative identification of objective and the legislative choice of means. The Charter rights we allege to have been abridged are not impaired "as little as possible", nor is the Act "sufficiently tailored to meet the legislative objective." 183

Neither are the effects of the legislation minor, especially when one considers that routine hospitalization, and transport to hospital for rural mothers, may actually place

The proposition that a restriction on a guaranteed right must be both rationally related to a permissible state objective and necessary for the attainment of that objective is clearly established in pre-Charter cases such as Solosky v. R.. [1980] S.C.R. 170 at 188; Prata v. Minister of Manpower and Immigration, [1976] I S.C.R. 376 at 382. For United States perspectives see Griswold v. Commecticut, supra, note 63 at 497.

180. E. Barrington, Midwifery is Catching, supra, note 48 at 124.

181. Supra, note 156.

182. Supra, note 168. Studies in Quebec and Ontario recommend midwives be paid on a salary, rather than a fee-for-service basis, and estimated these salaries at between $\$ 31,000$ and $\$ 43,000$ per year. In a 1986 Holland study "the cost savings associated with midwifery care ... were primarily related to the fact that midwives are paid less than physicians, and that home is a less expensive birthplace than hospital." "The Potential Requirement for Midwives" in Task Force, supra, note 4 at 167-68. Supra, note 46 at 564. 
mothers and infants at higher risk than they would otherwise experience at home. ${ }^{184}$ The evidence demonstrates that midwife-attended home births are both safe and costeffective whether in an urban or a rural setting. Whether one adopts arguments based on Charter s. 7 or s. 15, and whether from the perspective of the midwife or of the prospective mother, the result must surely be the elimination of the geographical restriction.

The particular prosecution that served as the initial focus for this paper was resolved, without elaboration, and possibly by adopting a particular interpretation of s. 76(5) and s. 77 of the Act. It is suggested that such an outcome was somewhat unfortunate, in that it indicated only implicit approval of the constitutional issues surrounding birthing decisions. A preferable legal solution would be to hold that to the extent that $\mathrm{s} .76$ in general and s. 76(5) in particular prohibit midwifery they are of no force and effect. This would ensure parental autonomy, midwife opportunity, and fetal safety within the framework of the World Health Organization's standards of midwifery as exemplified by the practices of the Alberta Association of Midwives and its members.

Such a solution leaves open the question of midwifery practice in hospital settings, and indeed the broader question of the statutory recognition of midwifery as a health discipline. However, if it can be demonstrated that midwifery provides a suitable standard of care for home births, the philosophical debate of whether midwives should be accorded hospital privileges is presumably solved. To elaborate that proposition as a constitutional right is a different question. It seems appropriate at this stage to leave the existing political and legislative processes to grapple with the issue.

184. Of particular note here is the fact that eliminating urban midwifery practice has resulted in the virtual eradication of rural midwifery practice. Then, to further complicate the picture, Alberta hospital policy requires rural VBAC, and other mothers perceived as "high-risk", to travel past local hospitals which could provide birthing assistance to regional hospitals which internal politics have decreed contain "optimum" medical facilities. This policy uncannily recreates the travelling scenario described in Morgentaler: "The enormous emotional and financial burden placed upon women who must travel long distances from home... is a burden created in many instances by Parliament." Supra, note 46 at 477 , and notes $124,125$. 